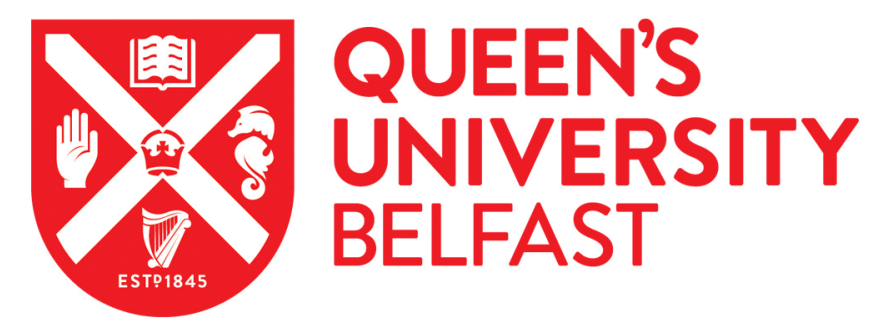

\title{
A drive-by inspection system via vehicle moving force identification
}

OBrien, E. J., McGetrick, P. J., \& Gonzalez, A. (2014). A drive-by inspection system via vehicle moving force identification. Smart Structures and Systems, 13(5), 821-848. https://doi.org/10.12989/sss.2014.13.5.821

\section{Published in:}

Smart Structures and Systems

\section{Document Version:}

Peer reviewed version

Queen's University Belfast - Research Portal:

Link to publication record in Queen's University Belfast Research Portal

Publisher rights

( 2014 KISTI Korean Institute of Science and Technology Information

\section{General rights}

Copyright for the publications made accessible via the Queen's University Belfast Research Portal is retained by the author(s) and / or other copyright owners and it is a condition of accessing these publications that users recognise and abide by the legal requirements associated with these rights.

Take down policy

The Research Portal is Queen's institutional repository that provides access to Queen's research output. Every effort has been made to ensure that content in the Research Portal does not infringe any person's rights, or applicable UK laws. If you discover content in the Research Portal that you believe breaches copyright or violates any law, please contact openaccess@qub.ac.uk. 


\title{
A drive-by inspection system via vehicle moving force identification \\ E.J. OBrien ${ }^{1 a}$, P.J. McGetrick ${ }^{{ }^{2 b}}$ and A. González ${ }^{10}$
}

\author{
${ }^{1}$ School of Civil, Structural \& Environmental Engineering, University College Dublin, Newstead, Belfield, Dublin 4, \\ Ireland \\ ${ }^{2}$ Dept. of Civil and Earth Resources Engineering, Kyoto University, Kyoto 615-8540, Japan
}

\begin{abstract}
This paper presents a novel method to carry out monitoring of transport infrastructure such as pavements and bridges through the analysis of vehicle accelerations. An algorithm is developed for the identification of dynamic vehicle-bridge interaction forces using the vehicle response. Moving force identification theory is applied to a vehicle model in order to identify these dynamic forces between the vehicle and the road and/or bridge. A coupled half-car vehicle-bridge interaction model is used in theoretical simulations to test the effectiveness of the approach in identifying the forces. The potential of the method to identify the global bending stiffness of the bridge and to predict the pavement roughness is presented. The method is tested for a range of bridge spans using theoretical simulations and the influences of road roughness and signal noise on the accuracy of the results are investigated.
\end{abstract}

Keywords: acceleration; bridge; global stiffness; inverse dynamics; road profiles; vehicle-bridge interaction; vehicle forces.

\section{Introduction}

The axle forces applied by a vehicle through its wheels are a critical part of the interaction between vehicles, pavements and bridges. It has been found that dynamic axle forces can increase the average road surface damage by up to four times compared to that caused by

\footnotetext{
${ }^{a}$ Professor, E-mail: eugene.obrien@ucd.ie

${ }^{*}$ C Corresponding Author. Assistant Professor, E-mail: mcgetrick.patrickjohn.5x@kyoto-u.ac.jp

${ }^{\mathrm{c} L e c t u r e r, \text { E-mail: arturo.gonzalez@ucd.ie }}$
} 
static axle forces alone (Cebon 1987, Cole and Cebon, 1992). Therefore, the minimisation of dynamic axle forces is important in order to promote long pavement life spans and ensure that bridge loads are small (Gillespie et al. 1992, Green and Cebon 1994, DIVINE 1997). Also, as the road surface roughness affects the vehicle dynamic forces (Cole et al. 1996, Kitching et al. 2000), it is generally accepted that the maintenance of road profiles for highways and bridges plays a major role. Sayers and Karamihas (1998) discuss several existing methods for the measurement of road profiles such as static manual methods (dipstick walking profilometers, rod and level) and more efficient dynamic approaches, such as inertial profilometers, which can measure profile tracks at highway speeds. The typical inertial profilometer consists of a vehicle equipped with a height sensing device, such as a laser, which measures pavement elevations at regular intervals (Sayers and Karamihas 1996, 1998) with the effects of vehicle dynamics removed from the elevation measurements via accelerometer(s). The method provides accurate, high resolution profile measurements but a drawback is the expense associated with laser-based technology.

For short to medium span bridges, the dynamic axle forces are of particular importance. In recent years there has been a significant amount of research carried out on the use of the moving force identification (MFI) technique to identify the vehicle-bridge interaction forces indirectly via measurements on the bridge. Yu and Chan (2007) provide a comprehensive literature review of this research. Methods which utilise the MFI technique can typically be categorised into one of two groups: (a) those which use discrete bridge models and the finite element (FE) method (Chan and Yung 2000, Law et al. 2004, Pinkaew 2006, Pinkaew and Asnachinda 2007) and (b) those which are based on an exact solution method including a form of system identification (Law et al. 1997, Chan et al. 1999, Yu and Chan 2003a, 2003b). The results from the latter group are sensitive to noise and exhibit fluctuations in the 
identified forces at the beginning and end of the time history which are the result of the illconditioned inverse problem. To provide smoother solutions and a bound to the identified forces, the Tikhonov regularisation method (Tikhonov and Arsenin 1977) is included in the solution (Zhu and Law 1999, 2000, 2001a, 2001b, 2002, 2003a, 2003b, 2006, Law and Zhu 2000, Law et al. 2001, Nordström 2006, Law et al. 2007, Gonzalez et al. 2008b, Deng and Cai 2010b, 2011). Recently, optimisation techniques have been developed for moving force identification which has led to methods which are based on genetic algorithms (Jiang et al. 2004, Au et al. 2004) (whereby interaction forces are calculated after estimating vehicle parameters) and simulated annealing genetic algorithms (Qu et al. 2011, Wang and Qu 2011). Also, Wu and Law (2011) investigate a stochastic vehicular axle load identification method, based on the Karhunen-Loève Expansion in which both the system parameters and excitation forces are assumed as Gaussian random processes. However, all of these approaches require instrumentation of the bridge to measure responses such as strains, displacements, accelerations and bending moments in order to identify the interaction forces. Also, usually it is necessary to obtain measurements at a number of locations and the installation of the equipment and data acquisition electronics can be time consuming and costly, limiting the implementation of this type of approach (Nagayama et al. 2007).

This paper proposes an alternative way to identify the dynamic interaction forces between the vehicle, pavement and bridge which involves direct instrumentation of a vehicle. The vehicle is fitted with accelerometers on each axle and MFI theory is applied to the vehicle equations of motion to obtain the interaction forces using the measured accelerations. The approach eliminates the need for any equipment to be installed on the bridge. To the authors' knowledge, this is the first investigation which applies MFI theory to the equations of a vehicle. Davis and Bunker (2007) provide a comprehensive review of existing methods which 
use on-vehicle instrumentation and measurements to obtain the wheel-force history. Such methods include wheel hub transducers, air spring pressure transducer systems, tyre pressure transducer systems, laser detectors, infrared sensors and combinations of strain gauges and accelerometers. These methods can be accurate but are also expensive and in some cases difficult to install. The low-cost approach presented in this paper has the benefit of only requiring the vehicle to be instrumented with accelerometers. It also has the potential to be developed for implementation as part of a drive-by inspection system (Kim and Kawatani 2009) for pavements and bridges.

For this theoretical investigation, the inverse problem is formulated as a non-linear least squares minimisation of the difference between measured and theoretical vehicle accelerations. First order Tikhonov regularisation is used to decrease errors due to illconditioning and the recursive least-squares problem is solved using the Dynamic Programming technique (Trujillo 1978) which has been utilised previously in force identification problems (Law and Fang 2001, Nordström 2006, González et al. 2008b). A coupled vehicle-bridge interaction (VBI) model is created in MATLAB (2005) to simulate 'measured' accelerations. The simulations are carried out for simply supported bridge spans of 15,25 and 35 metres and a vehicle speed of $80 \mathrm{~km} / \mathrm{h}(22 \mathrm{~m} / \mathrm{s})$. The influence of road roughness and noise on the force identification algorithm is investigated. The potential application of this method to predict road profile heights and monitor bridge stiffness is also investigated. Favourable conditions are identified in which this method can be used with a good degree of accuracy. 


\section{Coupled vehicle-bridge interaction model}

The coupling of the vehicle and bridge has been taken into account in many studies (Yang and Yau 1997, Henchi et al. 1998, Yang et al. 2004a, Kim et al. 2005, Deng and Cai 2010a). However it has been considered in only a small proportion of moving force identification problems (Chan et al. 1999, Law et al. 2004, Pinkaew 2006, Deng and Cai 2010b, Wu and Law 2011). In this paper, the vehicle-bridge interaction is modelled as a coupled system as the solution is given at each time step and no iteration is required in the computational process. The vehicle and bridge models are outlined in the following sections.

\subsection{Vehicle model}

The vehicle is represented here by a 4 degree-of-freedom half-car model, i.e. $n_{v}=4$, travelling at constant speed $c$ over a simply supported Finite Element (FE) beam (Fig. 1). While it is a simplified version of a vehicle, its response still illustrates many of the important characteristics of dynamic tyre forces (Cebon 1999). It is suitable for the approach presented in this paper as it provides measurements for two axles which enables the prediction of forces at each axle and displacements under each wheel. The four independent degrees of freedom correspond to sprung mass bounce displacement, $y_{s}$, sprung mass pitch rotation, $\theta_{s}$ and axle hop displacements of the unsprung masses at axle 1 and axle 2, $y_{u, 1}$ and $y_{u, 2}$ respectively. The vehicle body mass is represented by the sprung mass, $m_{s}$ and the axle components are represented by unsprung masses, $m_{u, 1}$ and $m_{u, 2}$. The sprung mass connects to the axle masses via a combination of springs of linear stiffness $K_{s, i}$ and viscous dampers with damping coefficients, $C_{s, i}$ which represent the suspension components for the front and rear axles $(i=$ 
1,2). The axle masses then connect to the road surface via springs with linear stiffnesses, $K_{t, i}$ which represent the tyre components for the front and rear axles $(i=1,2)$.

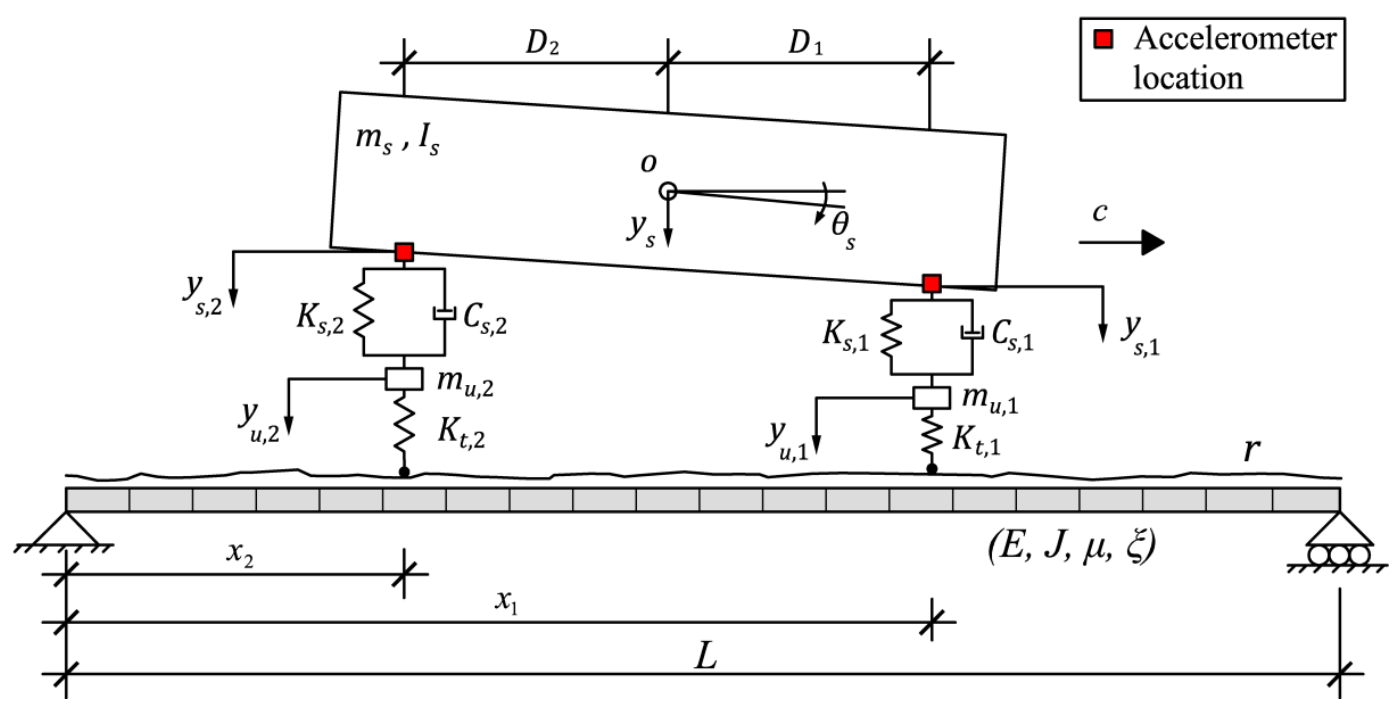

Fig. 1 Coupled vehicle-bridge interaction model

Other parameters of note are the sprung mass moment of inertia, $I_{S}$, and the distance of each axle to the vehicle's centre of gravity $(o)$, i.e., $D_{1}$ and $D_{2}$ in Fig. 1 . All the property values of the half-car are listed in Table 1 and are based on values gathered from the literature (Cebon 1999, Harris et al. 2007, González et al. 2010). The geometry is obtained from a manufacturer specification for an $18 \mathrm{t}$ two-axle truck (DAF 2011). The natural frequencies of vibration of the vehicle are given also; $f_{v, 1}, f_{v, 2}, f_{v, 3}$ and $f_{v, 4}$ which correspond to body bounce, body pitch and axle hop of the first and second axles respectively. It follows from Table 1 that the static axle loads of the vehicle are $P_{1}=86293 \mathrm{~N}$ and $P_{2}=90215 \mathrm{~N}$ for axles 1 and 2 respectively.

It is assumed that, for the purposes of force identification, all of the vehicle properties are known. In reality, the calibration of the vehicle model would be required before implementing the algorithm in order to obtain these properties. This involves the determination of the model properties based on measurements of the vehicle response to an excitation source, i.e., a 
known road profile or a bump using combinatorial optimisation (Harris et al. 2010), or a vibration test using modal analysis (Friswell and Mottershead 1995). In order to maintain a reasonable level of accuracy, the same calibrated vehicle would be used every time for implementation of the algorithm. Furthermore, in the study of a similar approach for the purpose of bridge damping identification, González et al. (2012) show that errors up to 5\% in the assumed vehicle properties do not significantly affect the accuracy of this type of algorithm.

Table 1 Vehicle model properties

\begin{tabular}{llcl}
\hline Property & Unit & Symbol & Value \\
\hline Body mass & $\mathrm{kg}$ & $m_{s}$ & 16200 \\
Axle mass & $\mathrm{kg}$ & $m_{u, 1}$ & 700 \\
& & $m_{u, 2}$ & 1100 \\
Suspension Stiffness & $\mathrm{N} \mathrm{m}^{-1}$ & $K_{s, 1}$ & $0.4 \times 10^{6}$ \\
& & $K_{s, 2}$ & $1 \times 10^{6}$ \\
Suspension Damping & $\mathrm{Ns} \mathrm{m}^{-1}$ & $C_{s, 1}$ & $10 \times 10^{3}$ \\
& & $C_{s, 2}$ & $20 \times 10^{3}$ \\
Tyre Stiffness & $\mathrm{N} \mathrm{m}{ }^{-1}$ & $K_{t, 1}$ & $1.75 \times 10^{6}$ \\
Pitch Moment of Inertia & $\mathrm{kg} \mathrm{m}$ & $K_{t, 2}$ & $3.5 \times 10^{6}$ \\
Distance of axle to centre of & & $I_{s}$ & 93457 \\
gravity & $\mathrm{m}$ & $D_{1}$ & 2.375 \\
Body mass frequency of & & $D_{2}$ & 2.375 \\
vibration & $\mathrm{Hz}$ & $f_{v, 1}$ & 1.00 \\
Axle mass frequency of & & $f_{v, 2}$ & 1.55 \\
vibration & $\mathrm{Hz}$ & $f_{v, 3}$ & 8.83 \\
\hline
\end{tabular}

The equations of motion of the vehicle are obtained by imposing equilibrium of all forces and moments acting on the vehicle and expressing them in terms of the degrees of freedom. They are given by:

$$
\mathbf{M}_{v} \ddot{\mathbf{y}}_{\mathbf{v}}+\mathbf{C}_{\mathrm{v}} \dot{\mathbf{y}}_{\mathbf{v}}+\mathbf{K}_{\mathrm{v}} \mathbf{y}_{\mathbf{v}}=\mathbf{f}_{\mathrm{v}}
$$


where $\mathbf{M}_{\mathbf{v}}, \mathbf{C}_{\mathbf{v}}$, and $\mathbf{K}_{\mathbf{v}}$ are, respectively, the mass, damping and stiffness matrices of the vehicle which are given in Appendix A. The displacement vector of the vehicle is, $\mathbf{y}_{\mathbf{v}}=$ $\left\{y_{s}, \theta_{s}, y_{u, 1}, y_{u, 2}\right\}^{\mathrm{T}}$. The vector, $\mathbf{f}_{\mathbf{v}}$ contains the time varying interaction forces applied by the vehicle.

$$
\mathbf{f}_{\mathbf{v}}=\left\{\begin{array}{llll}
0 & 0 & -F_{t, 1} & -F_{t, 2}
\end{array}\right\}^{\mathrm{T}}
$$

The term $F_{t, i}$ represents the dynamic interaction force at wheel $i$ :

$$
F_{t, i}=K_{t, i}\left(y_{u, i}-w_{v, i}\right) ; i=1,2
$$

where $w_{v, i}$ is the total displacement under wheel $i$. This parameter can be defined in terms of the road profile displacement and bridge displacement under wheel $i: r_{i}$ and $w_{b, i}$ respectively:

$$
w_{v, i}=w_{b, i}+r_{i} ; \quad i=1,2
$$

\subsection{Road profile generation and filtering}

A road profile is included in simulations for the coupled VBI model and the irregularities of this profile are randomly generated according to the ISO standard (ISO 8608 1995). Two road profile types are considered; a class 'A' road (very good profile, as expected in a well maintained highway) and a class 'C' road (average profile), having geometric spatial means of $8 \times 10^{-6}$ and $128 \times 10^{-6} \mathrm{~m}^{3} /$ cycle respectively. A $100 \mathrm{~m}$ approach length is included in the road profile prior to the bridge. A moving average filter is applied to the generated road profile heights, $r_{i}$, over a distance of $0.24 \mathrm{~m}$ to simulate the attenuation of short wavelength disturbances by the tyre contact patch (Harris et al. 2007). 


\subsection{Bridge model}

The bridge is represented by a simply supported FE beam model (Fig. 1) of total span length $L$. It consists of 20 discretised beam elements with 21 nodes; the elements have constant mass per unit length, $\mu$, modulus of elasticity $E$ and second moment of area $J$. There are 2 degrees of freedom per node to allow for a vertical translation and rotation at each node. Therefore, each element has 4 degrees of freedom and the beam model has a total of $n=42(2 \times 21)$ degrees of freedom. The response of a discretised beam model to a series of moving timevarying forces is given by the system of equations:

$$
\mathbf{M}_{\mathbf{b}} \ddot{\mathbf{w}}_{\mathbf{b}}+\mathbf{C}_{\mathbf{b}} \dot{\mathbf{w}}_{\mathbf{b}}+\mathbf{K}_{\mathbf{b}} \mathbf{w}_{\mathbf{b}}=\mathbf{N}_{\mathbf{b}} \mathbf{f}_{\mathrm{int}}
$$

where $\mathbf{M}_{\mathbf{b}}, \mathbf{C}_{\mathbf{b}}$ and $\mathbf{K}_{\mathbf{b}}$ are $(n \times n)$ global mass, damping and stiffness matrices of the beam model respectively, $\mathbf{w}_{\mathbf{b}}, \dot{\mathbf{w}}_{\mathbf{b}}$ and $\ddot{\mathbf{w}}_{\mathbf{b}}$ are the $(n \times 1)$ global vectors of nodal bridge displacements and rotations, their velocities and accelerations respectively, and the product, $\mathbf{N}_{\mathbf{b}} \mathbf{f}_{\text {int }}$ is the $(n \times 1)$ global vector of forces applied to the bridge nodes. The vector, $\mathbf{f}_{\text {int }}$ contains the interaction forces between the vehicle and the bridge and is described using the following $\left(n_{f} \times 1\right)$ vector:

$$
\mathbf{f}_{\text {int }}=\left\{\begin{array}{l}
P_{1}+F_{t, 1} \\
P_{2}+F_{t, 2}
\end{array}\right\}
$$

The matrix, $\mathbf{N}_{\mathbf{b}}$ is an $\left(n \times n_{f}\right)$ location matrix that distributes the $n_{f}$ applied interaction forces on beam elements to equivalent forces acting on the nodes; for the half-car model, $n_{f}=2$. The details of this matrix are given in Appendix A. This location matrix can be used to calculate the bridge displacement under each wheel, $w_{b, i}$, in Eq. (4) using: 


$$
\left\{\begin{array}{l}
w_{b, 1} \\
w_{b, 2}
\end{array}\right\}=\mathbf{N}_{\mathbf{b}}^{\mathrm{T}} \mathbf{w}_{\mathbf{b}}
$$

Rayleigh damping is adopted here to model viscous damping (Adhikari 2006) and it is given by:

$$
\mathbf{C}_{\mathbf{b}}=\alpha \mathbf{M}_{\mathbf{b}}+\beta \mathbf{K}_{\mathbf{b}}
$$

where $\alpha$ and $\beta$ are constants. The damping ratio $\xi$ is assumed to be the same for the first two modes and $\alpha$ and $\beta$ are obtained from $\alpha=2 \xi \omega_{1} \omega_{2} /\left(\omega_{1}+\omega_{2}\right)$ and $\beta=2 \xi /\left(\omega_{1}+\omega_{2}\right)$ where $\omega_{1}$ and $\omega_{2}$ are the first two natural frequencies of the bridge (Yang et al. 2004a). The properties of the three bridge spans used in this investigation are given in Table 2 and are based on typical concrete bridge cross-sections consisting of $\mathrm{T}$ beams, $\mathrm{Y}$ beams or Super-Y beams depending on the bridge span (BS5400-4 1990, Li 2006, Li et al. 2006, González et al. 2011). The Young's Modulus, $E$, for all spans is $3.5 \times 10^{10} \mathrm{~N} / \mathrm{m}^{2}$.

Table 2 Finite element beam properties

\begin{tabular}{cccccc}
\hline $\begin{array}{c}\text { Span } \\
\text { Length, } \\
L(\mathrm{~m})\end{array}$ & Type & $\begin{array}{c}\text { Stiffness, } E J \\
\left(\mathrm{~N} \mathrm{~m}^{2}\right)\end{array}$ & $\begin{array}{c}\text { Mass per unit } \\
\text { length, } \mu \\
(\mathrm{kg} / \mathrm{m})\end{array}$ & $\begin{array}{c}\text { Damping, } \\
\xi(\%)\end{array}$ & $\begin{array}{c}\text { 1st natural } \\
\text { frequency of } \\
\text { vibration, } \\
f_{b, 1}(\mathrm{~Hz})\end{array}$ \\
\hline 15 & T beam & $1.846 \times 10^{10}$ & 28125 & 3 & 5.66 \\
25 & $\begin{array}{c}\text { Y beam } \\
\text { Super Y } \\
\text { beam }\end{array}$ & $1.865 \times 10^{10}$ & 18358 & 3 & 4.09 \\
\hline
\end{tabular}

The bridge properties are not required for the force identification algorithm. However, for purposes of the bridge stiffness identification algorithm presented in Section 5.2, it is assumed 
that the bridge span length, $L$, mass per unit length, $\mu$, and damping, $\xi$, are known in advance. In practice, if these properties are unavailable or unknown, $L$ can be easily measured while $\mu$ can be estimated considering the bridge material and dimensions. The damping can be estimated from acceleration measurement(s) on the bridge using existing techniques such as the Random Decrement Technique (Ibrahim 1977, Asmussen et al. 1998, Liu et al. 2011) or Logarithmic Decrement (Clough and Penzien 1993, Tedesco et al. 1999, Gutenbrunner et al. 2007). It would only be necessary to carry out these procedures once for any particular bridge in order to establish an initial benchmark model for that bridge.

\subsection{Coupling of the vehicle-bridge system}

The dynamic interaction between the vehicle and the bridge is implemented in Matlab using the models described in this section. The vehicle and bridge are coupled at the tyre contact points via the interaction force $\mathbf{f}_{\text {int }}$ given in Eq. (6). Combining Eqs. (1) and (5), the coupled equation of motion is formed as:

$$
\mathbf{M}_{\mathbf{g}} \ddot{\mathbf{u}}+\mathbf{C}_{\mathbf{g}} \dot{\mathbf{u}}+\mathbf{K}_{\mathbf{g}} \mathbf{u}=\mathbf{f}
$$

where $\mathbf{M}_{\mathbf{g}}$ and $\mathbf{C}_{\mathbf{g}}$ are the combined system mass and damping matrices respectively, $\mathbf{K}_{\mathbf{g}}$ is the coupled time-varying system stiffness matrix and $\mathbf{f}$ is the system force vector (see Appendix A). The vector, $\mathbf{u}=\left\{\mathbf{y}_{\mathbf{v}}, \mathbf{w}_{\mathbf{b}}\right\}^{\mathbf{T}}$ is the displacement vector of the system. The equations of motion for the coupled system are solved using the Wilson-Theta integration scheme (Bathe and Wilson 1976, Tedesco et al. 1999). The optimal value of the parameter $\theta=1.420815$ is used for unconditional stability in the integration scheme (Weaver and Johnston 1987). 
In simulations, it is assumed that there are two measurement sources obtained as input for the algorithm. These are sprung mass accelerations above the suspension of each axle (Fig. 1) and are described using the following equation:

$$
\ddot{y}_{s, i}=\ddot{y}_{s}-(-1)^{i} D_{i} \ddot{\theta}_{s} ; i=1,2
$$

In practice it is expected that the accuracy of measurements will be lower than in theoretical simulations due to errors such as random noise. Therefore the measured accelerations are contaminated with noise using an additive noise model based on signal-to-noise ratios (SNRs) of 20, 10 and 5 (i.e., relative error in the measurements of $5 \%, 10 \%$ and $20 \%$ respectively). Noise is randomly added to the true accelerations by sampling a Normal distribution of zero mean with standard deviation equal to the standard deviation of the true acceleration data divided by the SNR (Harris et al. 2010).

\section{Identification of dynamic axle forces}

The vehicle force identification (VFI) algorithm presented in this paper involves two main steps: 1) state space formulation of the vehicle equations of motion for the Dynamic Programming (DP) technique and 2) Tikhonov regularisation and the L-curve method. It has been adapted from the MFI algorithm described in detail by González et al. (2008b) and only the features which are unique to this paper are presented.

The (DP) technique is effectively a recurrence algorithm that may be used to solve large least squares problems. It was first formulated by Trujillo (1978) and it has been implemented for moving force identification problems which include zeroth order regularisation with the 
optimal state estimation approach (Law and Fang 2001), and in generalised solutions to moving force identification which use higher order Tikhonov regularisation (Nordström 2006, González et al. 2008b). Lourens et al. (2012) propose an augmented Kalman filter (AKF) technique as an alternative to the DP technique. However, it was found that the AKF technique only outperforms the DP technique when the measurements are close to the applied force.

\subsection{State-space formulation of vehicle model}

Using a state space formulation for the vehicle model, Eq. (1) is converted into a vector matrix differential equation:

$$
\dot{\mathbf{X}}=\mathbf{A X}+\overline{\mathbf{f}_{\mathbf{v}}}
$$

with the $(8 \times 1)$ state variable vector $\mathbf{X}$ defined by,

$$
\mathbf{X}=\left\{\begin{array}{c}
\mathbf{y}_{\mathbf{v}} \\
\dot{\mathbf{y}}_{\mathbf{v}}
\end{array}\right\}
$$

and where

$$
\mathbf{A}=\left[\begin{array}{cc}
0 & \mathbf{I} \\
-\mathbf{M}_{\mathbf{v}}^{-1} \mathbf{K}_{\mathbf{v}} & -\mathbf{M}_{\mathbf{v}}^{-1} \mathbf{C}_{\mathbf{v}}
\end{array}\right], \quad \overline{\mathbf{f}_{\mathbf{v}}}=\left[\begin{array}{c}
\mathbf{0} \\
\mathbf{M}_{\mathbf{v}}^{-1} \mathbf{f}_{\mathbf{v}}
\end{array}\right]
$$

The differential equation is rewritten in standard exponential matrix representation which is often referred to as a zeroth order system (Trujillo and Busby 1997):

$$
\mathbf{X}_{j+1}=\mathbf{M} \mathbf{X}_{j}+\mathbf{G g}_{j} ; j=1, \ldots, N
$$


where $\mathbf{M}=e^{\mathbf{A} h}$ for time step $h$ and $\mathbf{g}_{j}=\left\{-F_{t, 1},-F_{t, 2}\right\}^{\mathrm{T}}$ contains the forces to be predicted. The scalar, $N$ is the total number of discrete measurements. The matrix, $\mathbf{G}$ relates the forces $\mathbf{g}_{j}$ to the system and is defined by,

$$
\mathbf{G}=\left(\mathbf{A}^{-\mathbf{1}}(\mathbf{M}-\mathbf{I})\right)\left[\begin{array}{c}
\mathbf{0} \\
-\mathbf{M}_{\mathbf{v}}^{-1} \mathbf{L}_{\mathbf{v}}
\end{array}\right]
$$

with the $(4 \times 2)$ location sub-matrix $\mathbf{L}_{\mathbf{v}}=\left[\begin{array}{ll}\mathbf{0} & \mathbf{I}\end{array}\right]^{\mathbf{T}}$.

In first order regularisation, the derivative of the forces is regularised which reduces the error and provides a smoother solution than the zeroth order system (Busby and Trujillo 1997, González et al. 2008b). To facilitate this, Eq. (14) is now converted into a first order system with the forces to predict included in a new state variable vector, $\widehat{\mathbf{X}}_{j}=\left[\mathbf{X}_{j} \mathbf{g}_{j}\right]^{\mathbf{T}}$, with the vector $\mathbf{r}$ containing the derivative of the forces:

$$
\widehat{\mathbf{X}}_{j+1}=\left[\begin{array}{cc}
\mathbf{M} & \mathbf{G} \\
0 & \mathbf{I}
\end{array}\right] \widehat{\mathbf{X}}_{j}+\left[\begin{array}{l}
0 \\
\mathbf{I}
\end{array}\right] \mathbf{r}_{j} ; \quad j=1, \ldots, N
$$

\section{Measurements}

The acceleration measurements taken on the vehicle are represented by the $(m \times 1)$ vector $\mathbf{d}_{j}$. In this case, with two acceleration measurements, $m=2$. They must be related to the state variables to allow the least squares formulation of the problem. Using a selection matrix $\mathbf{Q}$, the relationship between measurements and the state variables $\widehat{\mathbf{X}}_{j}$, is given by:

$$
\mathbf{d}_{j}=\mathbf{Q} \widehat{\mathbf{X}}_{j}
$$


As $\widehat{\mathbf{X}}_{j}$ is a $\left(\left(2 n_{v}+n_{f}\right) \times 1\right)$ vector, it follows that $\mathbf{Q}$ is of size $\left(m \times\left(2 n_{v}+n_{f}\right)\right)$, i.e., it is a $(2 \times$ 10) matrix.

\subsection{Tikhonov regularisation and the L-curve method}

The second step of this approach involves the use of a regularisation parameter to improve the conditioning of the system. Tikhonov regularization (Tikhonov and Arsenin 1977) adds an optimum regularization parameter, $\lambda$, to the equations of the ill-conditioned least squares problem to control smoothness of the solution and provide bounds to the error. The optimal value for $\lambda$ is obtained using Hansen's L-Curve (Hansen 1992, Busby and Trujillo 1997). The method is described in detail by González et al. (2008b). For this approach the L-curve is plotted on a log-log scale using the following norms:

$$
\begin{gathered}
E_{\text {norm }}=\sqrt{\sum_{k=1}^{m}\left(\mathbf{d}_{k}-\mathbf{Q} \widehat{\mathbf{X}}_{k}, \mathbf{W}\left(\mathbf{d}_{k}-\mathbf{Q} \widehat{\mathbf{X}}_{k}\right)\right)} \\
F_{\text {norm }}=\sqrt{\sum_{k=1}^{m}\left(\mathbf{r}_{k}, \mathbf{r}_{k}\right)}
\end{gathered}
$$

where $\mathbf{W}$ is an $(m \times m)$ identity matrix and $(\mathbf{x}, \mathbf{y})$ denotes the vector product of $\mathbf{x}$ and $\mathbf{y}$, i.e., in this case, for terms corresponding to measurement $k,\left(\mathbf{x}_{k}, \mathbf{y}_{k}\right)=\sum_{j=1}^{N} \mathbf{x}_{k, j} \mathbf{y}_{k, j}$. The optimal value for $\lambda$ corresponds to the point of maximum positive curvature on the L-curve plot. If $\lambda$ approaches zero, the least squares problem tends toward that of standard least squares minimisation; conversely, if $\lambda$ is very large the solution norm is small but provides a 
large residual norm hence the least squares error is large. Therefore, the optimal value of $\lambda$ provides a trade-off between the residual norm and the solution norm.

\section{Simulation results and discussion}

In this section, the results of the dynamic force identification algorithm outlined in Section 3 are presented.

\subsection{Simulated Acceleration Measurements}

The method proposed in this paper requires only the measurement of vehicle accelerations to identify the vehicle dynamic interaction forces. For the purposes of this theoretical investigation, 'measured' accelerations (Eq. (10)) are simulated artificially at a sampling frequency of $1000 \mathrm{~Hz}$ for bridge spans of 15, 25 and 35 metres, very good and average road profiles and a vehicle speed of $22 \mathrm{~m} / \mathrm{s}(80 \mathrm{~km} / \mathrm{h})$. Fig. 2 shows an example of the simulated and noise-contaminated accelerations generated by the VBI model for the $15 \mathrm{~m}$ bridge span.

Given the axle spacing of $4.75 \mathrm{~m}$, the $2^{\text {nd }}$ axle enters the bridge at 0.214 seconds and the $1^{\text {st }}$ axle exits at 0.675 seconds. 

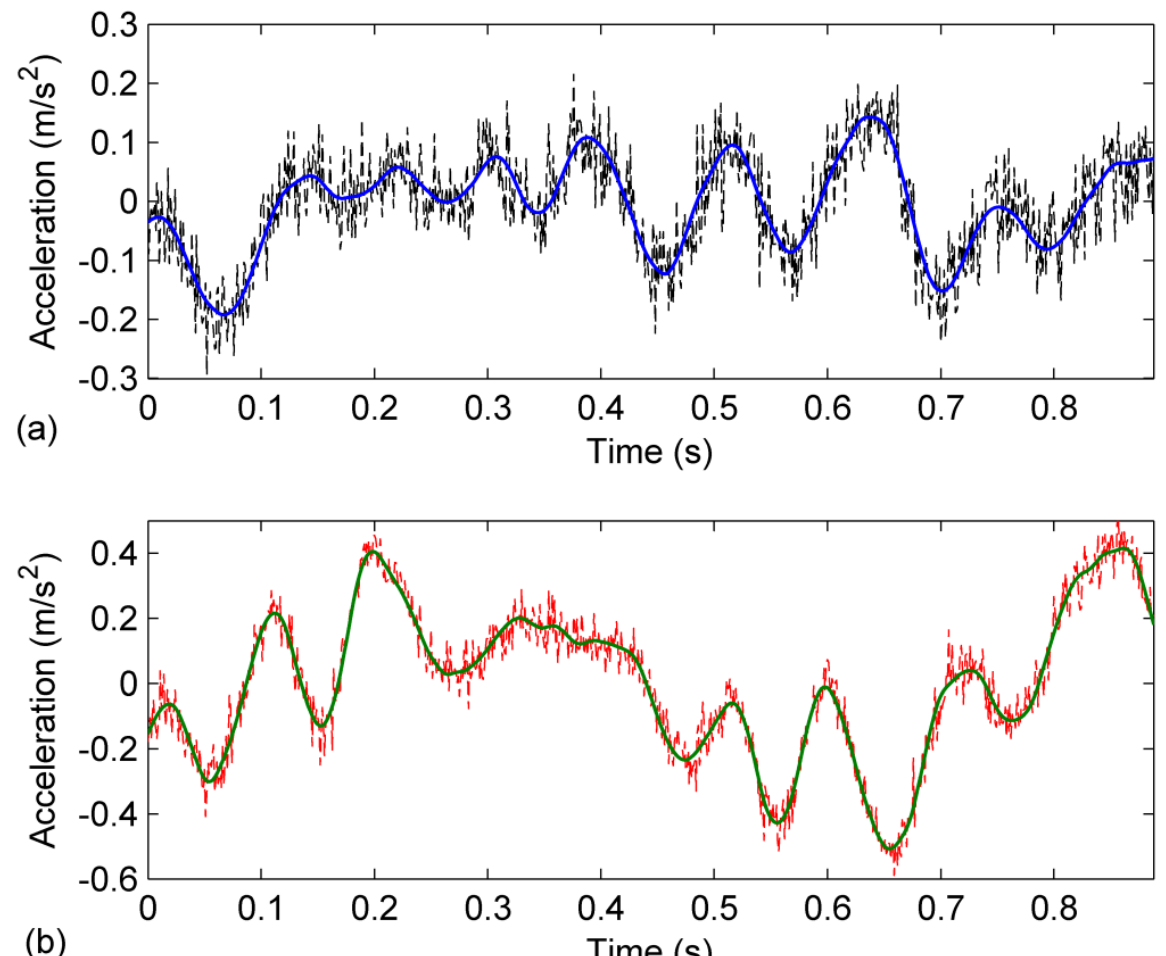

(b)

Fig. 2 'Measured' vehicle accelerations for vehicle travelling at $22 \mathrm{~m} / \mathrm{s}$ across a $15 \mathrm{~m}$ bridge on a very good road profile; (a) true (-) and corrupted (---) accelerations over axle 1, (b) true (-) and corrupted (---) accelerations over axle 2 with $\mathrm{SNR}=5$.

\subsection{L-curve and optimal regularisation parameter}

Fig. 3 shows the L-curve obtained for the vehicle travelling at $22 \mathrm{~m} / \mathrm{s}$ across the $15 \mathrm{~m}$ bridge span on the very good road profile. The optimal regularisation parameter $\lambda$ is obtained as 2.2 $\times 10^{-8}$ and it is indicated in the figure at the point of maximum positive curvature at the corner of the L-curve. 


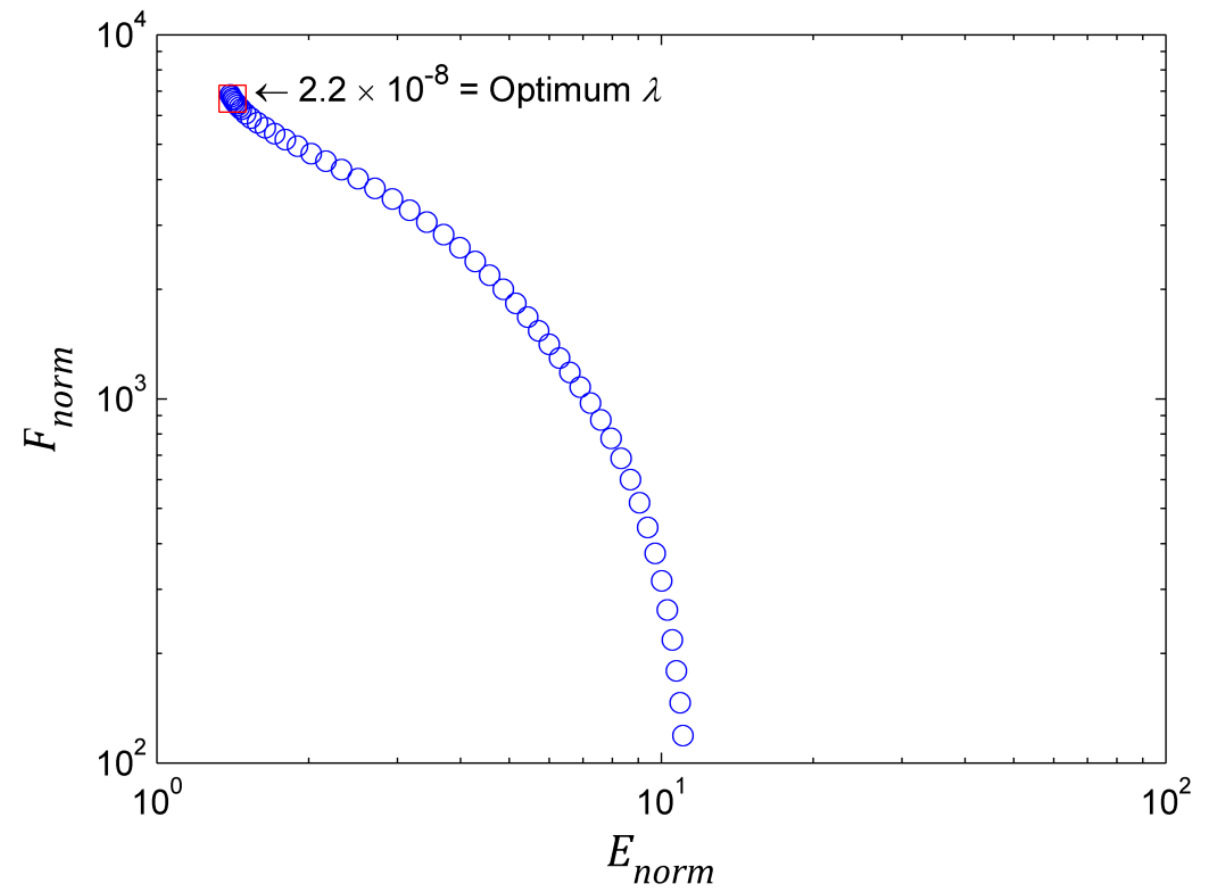

Fig. 3 L-curve due to vehicle travelling across $15 \mathrm{~m}$ bridge at $22 \mathrm{~m} / \mathrm{s}$ for $\lambda$ values between 1.5 $\times 10^{-8}$ and $1 \times 10^{-3}$ and SNR $=10$ on very good road profile.

\subsection{Identified forces for very good road profile}

Fig. 4 shows the identified dynamic axle forces corresponding to the L-curve shown in Fig. 3 . It can be seen that the algorithm identifies the true forces accurately, which are dominated here by the axle hop frequencies. However, due to the smoothing of the solution by the regularisation parameter, the identified forces do not predict some of the higher frequency components of the true forces accurately. Nevertheless, the larger amplitude components of the true forces are predicted very well. These large amplitude peaks are an important factor in relation to pavement and bridge damage as they can indicate specific locations in pavements where damage will be concentrated (Cole et al. 1996, Kitching et al. 2000), a phenomenon known as spatial repeatability (Cole and Cebon 1992). 

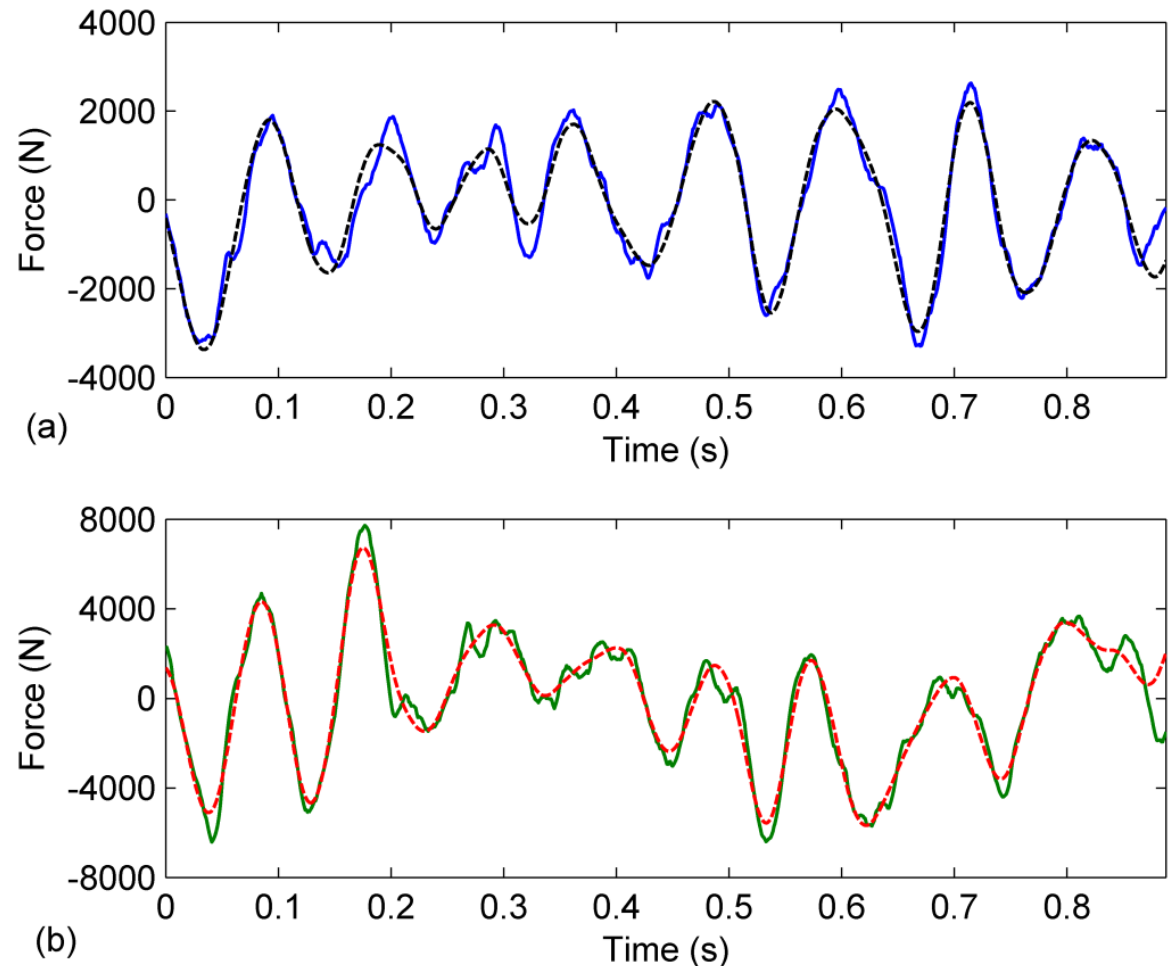

Fig. 4 Identified dynamic axle forces for vehicle travelling across $15 \mathrm{~m}$ bridge at $22 \mathrm{~m} / \mathrm{s}$ with $\lambda$ $=2.2 \times 10^{-8}$ and SNR $=10$ for very good road profile. (a) True $(-)$ and identified forces (---) at axle 1, (b) True (- - and identified forces at axle $2(---)$.

Table 3 presents the Root Mean Square Error (RMSE) of the identified forces expressed as a percentage of the maximum absolute true force magnitude. The percentage RMSEs are given for each bridge span and SNR investigated. The RMSE for each identified axle force is calculated using the equation,

$$
\mathrm{RMSE}=\sqrt{\frac{1}{N} \sum_{j=1}^{N}\left(F_{\text {est }, j}-F_{\text {true }, j}\right)^{2}}
$$

where $F_{e s t, j}$ and $F_{t r u e, j}$ are the predicted and true forces respectively at each point in time, $j$. The errors observed here are primarily consequences of the presence of high frequency 
components in the dynamic axle force history. However, the errors are less than $10 \%$ except for the identified forces at axle 1 for the lowest SNR of 5, which gives an error of $10.5 \%$.

In general, the results for the second axle are slightly more accurate. This is due to the properties of the second axle; its mass, damping and stiffness are on average twice as large as the corresponding properties of the first axle (Table 1). In particular, Eq. (3) shows that a larger stiffness value for $K_{t, i}$ will result in a larger dynamic axle force as $y_{u, i}$ and $w_{v, i}$ will be of similar magnitude for $i=1,2$. This can be seen by examining Fig. 4 and comparing the dynamic force magnitudes of axle 1 and axle 2; axle 2 forces are larger. Furthermore, the absolute errors in the dynamic forces obtained for each axle from the algorithm are, in general, relatively closer in magnitude than their respective maximum absolute true dynamic force magnitudes, i.e., the absolute errors are less dependent than the maximum forces on the axle properties. Hence, as percentage RMSE is tabulated in Table 3, the percentage errors for axle 2 are typically lower.

Nevertheless, similar accuracy is obtained for each bridge span and axle force although the 25 $\mathrm{m}$ bridge span displays the least error overall for forces of the second axle. Finally, the values in this table suggest that the identified forces are not very sensitive to the measurement noise level as there are only slight increases in error as the SNR decreases. 
Table 3 Percentage RMSE of identified dynamic axle forces on very good road profile

\begin{tabular}{ccccccc}
\hline \multicolumn{2}{c}{ 15 $\mathrm{m}$ Span } & \multicolumn{2}{c}{ RMSE (\%) } \\
\multicolumn{1}{c}{ 25 m Span } & \multicolumn{2}{c}{$35 \mathrm{~m}$ Span } \\
\hline SNR & Axle 1 & Axle 2 & Axle 1 & Axle 2 & Axle 1 & Axle 2 \\
\hline 20 & 9.89 & 8.28 & 6.91 & 5.51 & 7.01 & 7.65 \\
10 & 9.94 & 8.37 & 7.20 & 5.55 & 7.22 & 7.86 \\
5 & 10.50 & 8.66 & 8.23 & 5.83 & 7.99 & 8.45 \\
\hline
\end{tabular}

\subsection{Identified forces for average road profile}

This section presents the identified dynamic axle forces with the average road profile included in simulations. An example of the identified forces for the vehicle crossing the $15 \mathrm{~m}$ bridge span with this road profile is given in Fig. 5. The scale of the y-axis in this figure compared to that of Fig. 4 indicates the effect of increasing the road roughness. Despite the poorer road surface, the algorithm again predicts the dynamic axle forces very well. Also, similar to the results for the very good profile, it can be seen that the algorithm does not predict some of the higher frequency components. The percentage RMS errors of the identified forces, calculated using Eq. (20), are given in Table 4 for all bridge spans and noise levels investigated. Once again, the errors observed here can be attributed to high frequency components of the dynamic axle forces and the second axle is found to be more accurate. As this is observed for both road profiles investigated, it suggests that in general, a vehicle axle of greater stiffness may provide an improvement in identification accuracy. Aside from the forces of the first axle on the $35 \mathrm{~m}$ span, all of the errors are less than $10 \%$ once again which indicates that the identification procedure is not very sensitive to the road profile roughness. 


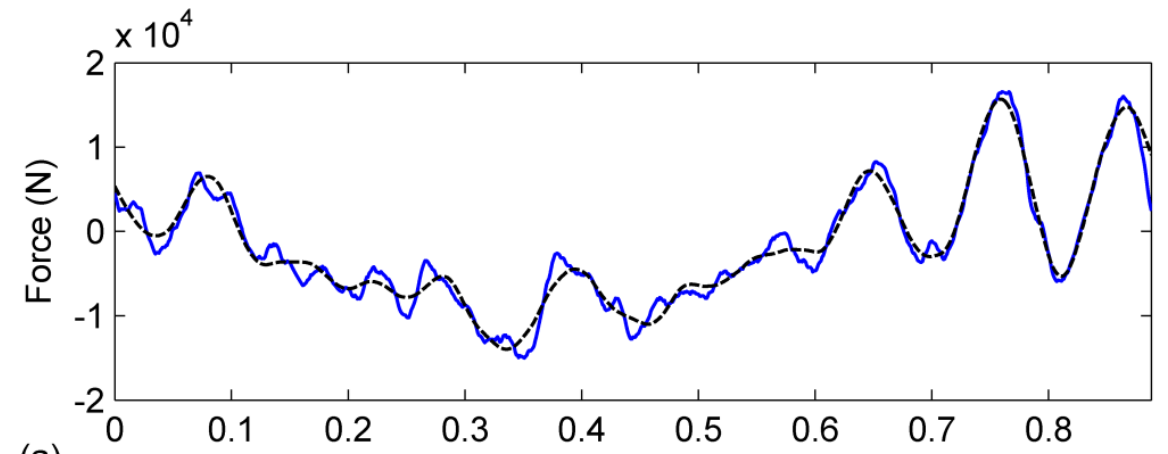

(a)

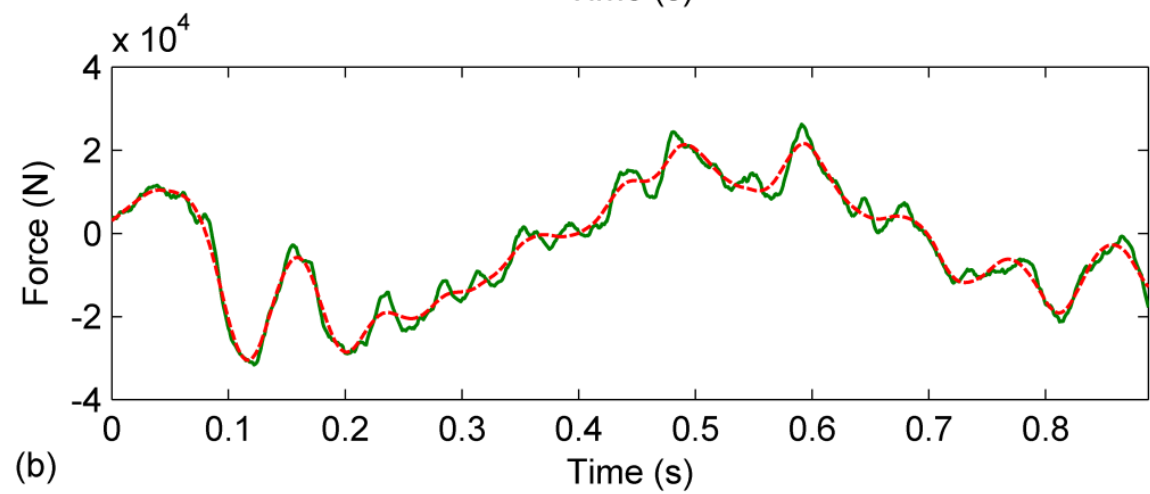

Fig. 5 Identified dynamic axle forces for vehicle travelling across $15 \mathrm{~m}$ bridge at $22 \mathrm{~m} / \mathrm{s}$ with $\lambda$ $=2.4 \times 10^{-8}$ and SNR $=10$ for average road profile. (a) True $(-)$ and identified forces (---) at axle 1, (b) True (- - ) and identified forces at axle $2(---)$.

For the poorer road surface and the $15 \mathrm{~m}$ bridge span, the algorithm identifies the forces more accurately than for the very good road profile. This can be explained by inspecting Fig. 5. For both axles there is a large amplitude low frequency element in the force history which the algorithm can identify very well; it is clearest in Fig. 5(b) between 0.2 and 0.8 seconds, while the magnitude of the higher frequency components is relatively small in comparison. This low frequency corresponds to the body bounce and pitch of the vehicle and was not excited as much by the very good road profile on the $15 \mathrm{~m}$ bridge (Fig. 4). Although there is a small decrease in accuracy with increasing noise level, overall the algorithm is not very sensitive to noise, as was found from simulations with the very good road profile. 
Table 4 Percentage RMSE of identified dynamic axle forces on average road profile

\begin{tabular}{ccccccc}
\hline \multicolumn{2}{c}{ 15 m Span } & \multicolumn{2}{c}{$\begin{array}{c}\text { RMSE (\%) } \\
25 \mathrm{~m} \mathrm{Span}\end{array}$} & \multicolumn{2}{c}{$35 \mathrm{~m}$ Span } \\
\hline SNR & Axle 1 & Axle 2 & Axle 1 & Axle 2 & Axle 1 & Axle 2 \\
\hline 20 & 7.74 & 6.30 & 8.86 & 5.91 & 12.06 & 6.62 \\
10 & 7.96 & 6.38 & 9.08 & 5.87 & 12.13 & 6.78 \\
5 & 8.70 & 6.68 & 9.81 & 5.92 & 12.71 & 7.20 \\
\hline
\end{tabular}

\section{Implementation of a drive-by inspection algorithm}

It has been shown that the force identification algorithm presented in Sections 3 and 4 can accurately predict the dynamic axle forces of a vehicle as it crosses a bridge with a road surface roughness. These forces define the interaction between the vehicle, pavement and bridge and consequently will be affected by any change in the properties of the system. Therefore, in this paper it is proposed to develop the force identification approach further by implementing it as a tool for the condition monitoring of pavements and bridges.

In recent years, a body of research has been carried out on the use of instrumented vehicles for the monitoring of infrastructure such as pavements and bridges, including investigations of low-cost approaches utilising vehicle acceleration measurements. For example, a frequency domain road classification method is proposed by González et al. (2008a) which is based on the relationship between the power spectral densities of vehicle accelerations and road profile via a transfer function. Harris et al. (2010) investigate a method which employs a combinatorial optimisation technique to identify road profile heights from the vehicle acceleration response, with only a priori knowledge of the vehicle dynamic properties required. 
The feasibility of extracting bridge dynamic parameters, such as damping and frequency, from the vehicle response has been verified theoretically (Yang et al. 2004b, McGetrick et al. 2009, González et al. 2010) and it has also been tested in field trials (Lin and Yang 2005, Oshima et al. 2008, Yang and Chang 2009a). Parametric studies have been carried out which indicate favourable conditions for its implementation (Yang and Chang 2009b). In addition, experimental investigations have been conducted to check the feasibility of the approach as part of a drive-by inspection system for bridge monitoring (Oshima et al. 2008, Kim and Kawatani 2009, Toshinami et al. 2009). In this section, the drive-by approach is developed for both the characterisation of road profiles and bridge condition monitoring. An algorithm is developed for the purpose of monitoring bridge condition which aims to detect any change in behaviour of the structure which might be an indicator of some form of damage, e.g., corrosion or cracking.

\subsection{Prediction of road profile heights}

In the force identification algorithm, the predicted force vector $\mathbf{g}_{j}$ provides the dynamic forces applied to the vehicle, $F_{t, 1}$ and $F_{t, 2}$ (Eq. (3)). The axle displacements $y_{u, i}$ are also predicted as

part of the state variable vector, $\widehat{\mathbf{X}}$. As the tyre stiffness $K_{t, i}$ is known for each tyre $i$, the predicted displacement under wheel $i, w_{v, i}$, can be obtained from Eq. (3). For the scenario where the vehicle forces are predicted as the vehicle travels over a road pavement only (i.e., $w_{b, i}=0$ in Eq. (4)), $w_{v, i}$ is effectively a prediction of the road profile heights experienced by wheel $i$. The IRI ratings and the Power Spectral Densities (PSDs) of true and predicted road profiles are compared and this analysis is carried out using ProVAL (Profile Viewing and AnaLysis; Chang et al. 2006). 
The results of a pavement profile prediction for the very good profile are presented in Fig. 6 . The length of the predicted profile is $100 \mathrm{~m}$ and the measured acceleration data is obtained from the approach prior to the bridge. For this result, accelerations were contaminated with noise having an SNR of 10. The prediction is very good overall. However, similar to the identified forces in Section 4, it can be seen that there are low frequency discrepancies at the beginning and end of the profile and some of the very small higher frequency irregularities are not identified.

The results of a pavement profile prediction for the average-quality profile are presented in Fig. 7. The results are similar to those for the very good profile. Here, the low frequency, long wavelength error has manifested itself as a shifted estimate for the road profile under the first wheel. This type of error can be attributed to the acceleration measurements' poor sensitivity to lower frequency responses approaching the static frequency at $0 \mathrm{~Hz}$.

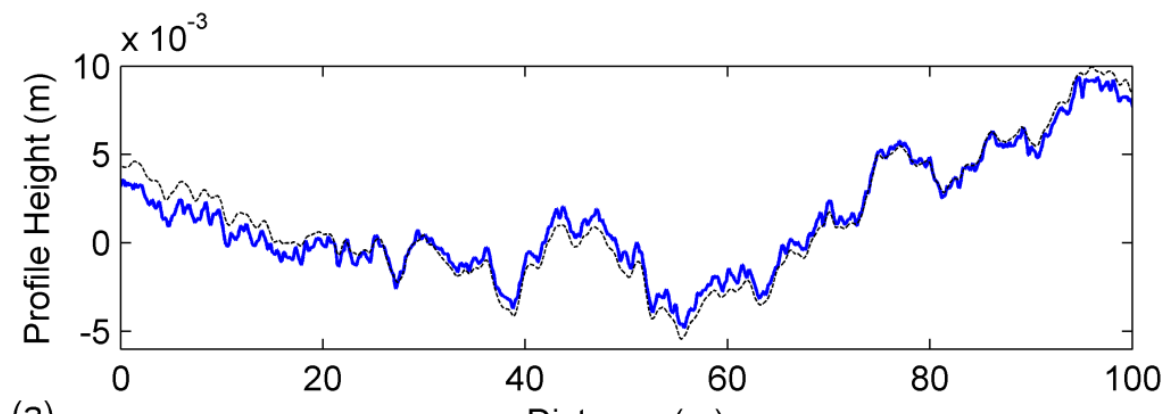

(a)

Distance $(\mathrm{m})$

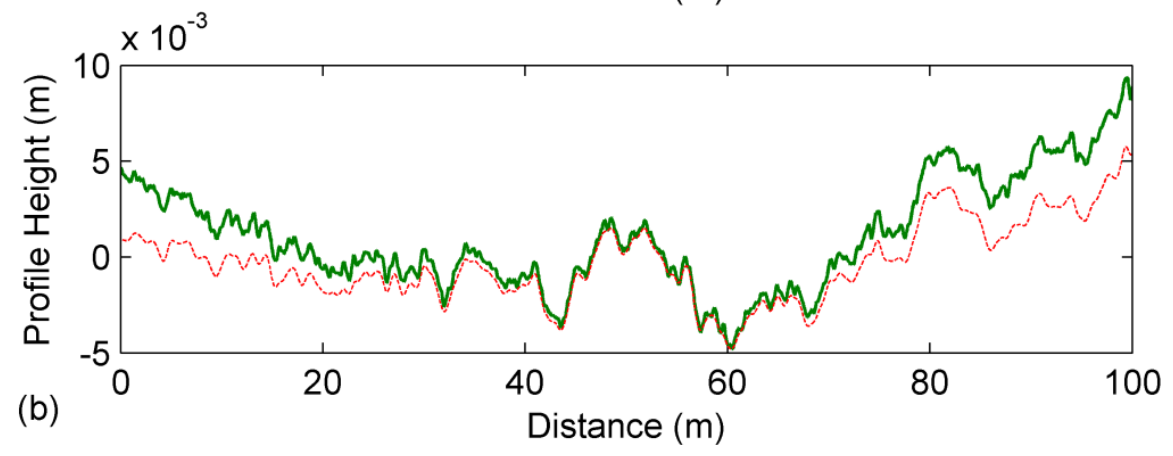

Fig. 6 Identified profile heights for very good road with $S N R=10$. (a) True $(\longrightarrow$ and predicted (---) profiles at axle 1, (b) True (_- ) and predicted (---) profiles at axle 


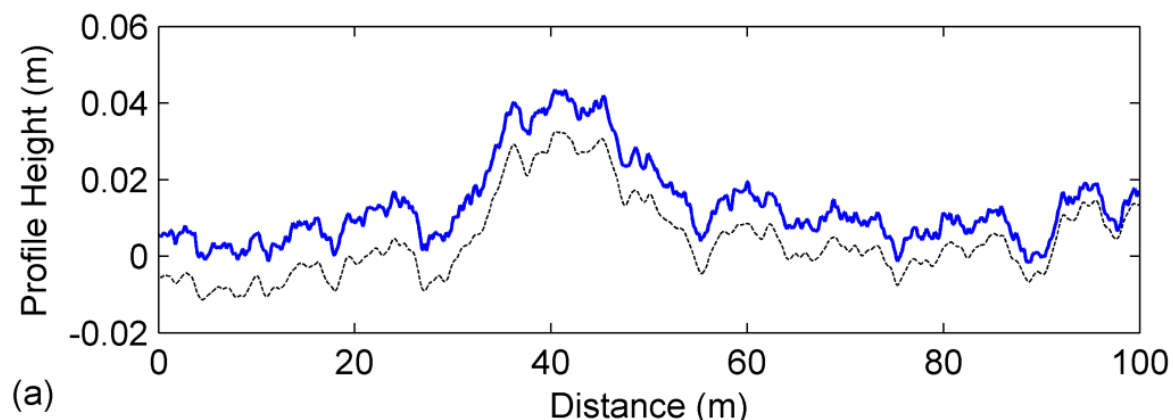

(a)

Distance $(\mathrm{m})$

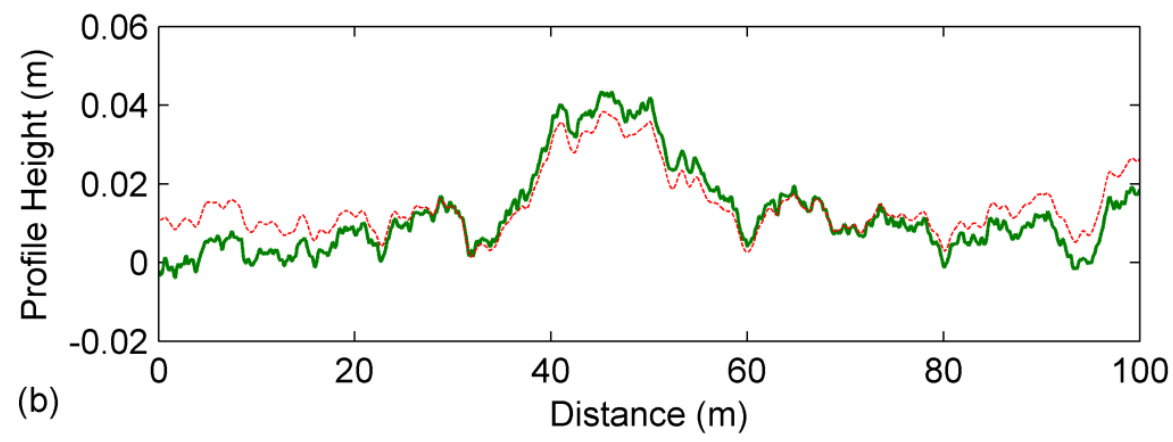

Fig. 7 Identified profile heights for average road with $\mathrm{SNR}=10$. (a) True (-) and predicted (---) profiles at axle 1, (b) True (- $)$ and predicted (---) profiles at axle 2.

In order to assess the profile characterisation accuracy of the algorithm, the PSDs of the road profile heights under each wheel for the very good and average profiles are plotted on log-log scales in Fig. 8 and Fig. 9 respectively. The larger magnitude, low frequency discrepancies observed in Fig. 6 and Fig. 7 occur here as relatively small errors in terms of profile characterisation on the log-log scale. However, it is clear from these figures that the errors in characterising the true road profile heights are primarily caused by the short wavelength, high frequency errors. As has already been highlighted, these are a result of the regularisation in the algorithm which smoothes the solution. It can be inferred from the spectra that the predicted profiles characterise the true profiles with high accuracy for the frequency band between 0.03 cycles/m and 0.8 cycles/m approximately. 

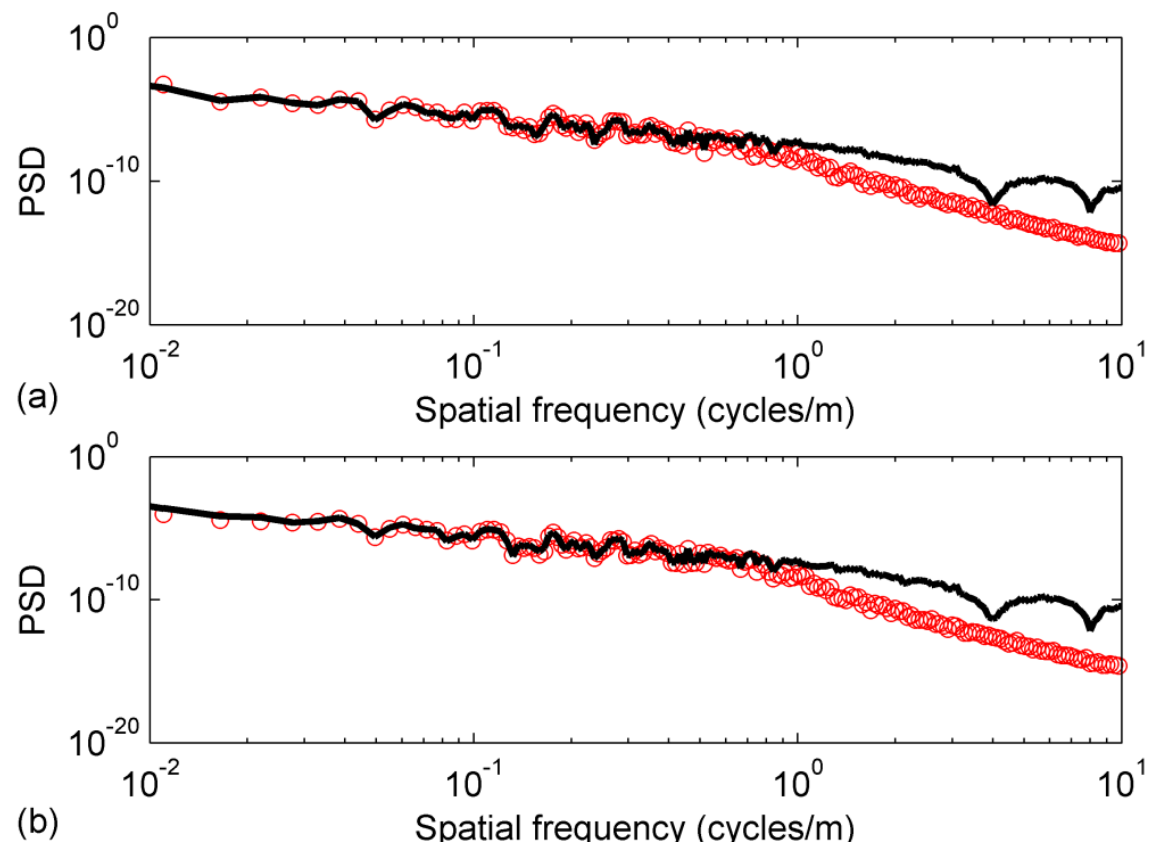

Fig. 8 PSD of very good road profile heights under (a) wheel 1 and (b) wheel 2 for SNR $=10$.

True profile PSD (—) ; predicted profile PSD (०).

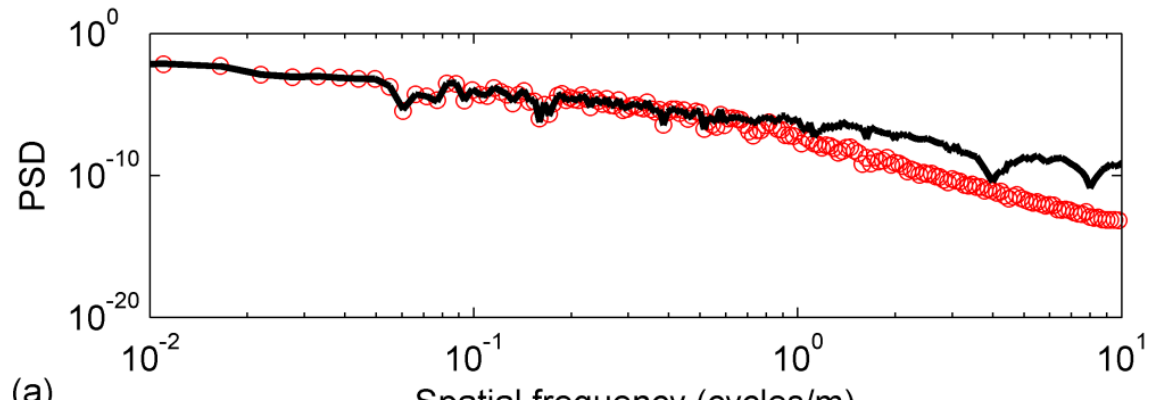

(a)

Spatial frequency (cycles $/ \mathrm{m})$

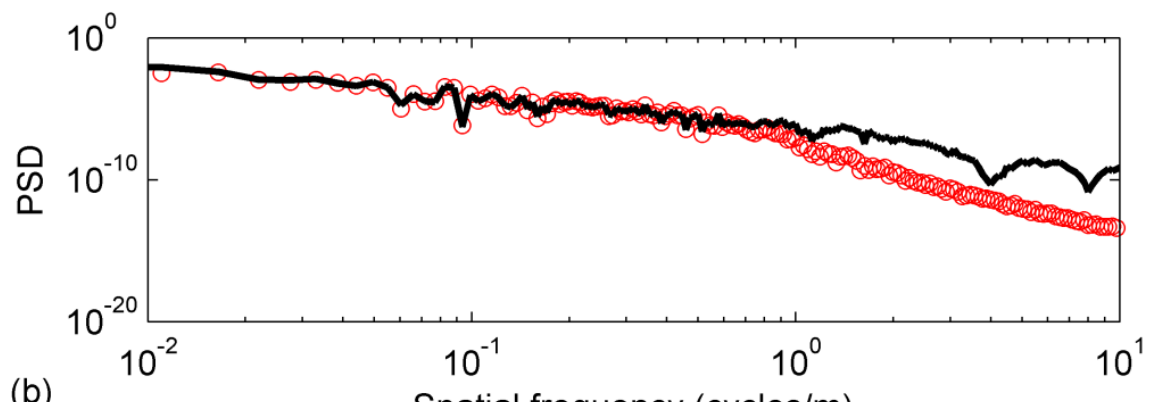

(b)

Spatial frequency (cycles $/ \mathrm{m})$

Fig. 9 PSD of average road profile heights under (a) wheel 1 and (b) wheel 2 for SNR $=10$.

True profile PSD (-) ; predicted profile PSD (०). 
The IRI values of the predicted profiles are presented in Table 5. The percentage errors are also tabulated. As before, results for the profile under wheel 2 are more accurate. The errors are all less than $10 \%$ and underestimate the IRI values. This relates to the poor estimation of higher frequency components of the road profile.

Table 5 Predicted IRI values and percentage error for very good and average profiles

\begin{tabular}{cccccc}
\hline \multirow{2}{*}{ Profile } & \multirow{2}{*}{$\mathrm{SNR}$} & \multicolumn{2}{c}{$\operatorname{IRI}_{1 \text { st profile }}(\mathrm{m} / \mathrm{km})$} & \multicolumn{2}{c}{$\operatorname{IRI}_{\text {2nd profile }}(\mathrm{m} / \mathrm{km})$} \\
\cline { 3 - 6 } & & Predicted & \% Error & Predicted & $\%$ Error \\
\hline \multirow{2}{*}{$\mathrm{A}$} & 20 & 0.97 & -8.49 & 0.99 & -6.60 \\
& 10 & 0.97 & -8.49 & 0.99 & -6.60 \\
& 5 & 0.99 & -6.60 & 0.99 & -6.60 \\
\hline \multirow{2}{*}{$\mathrm{C}$} & 20 & 4.20 & -7.28 & 4.25 & -6.18 \\
& 10 & 4.20 & -7.28 & 4.25 & -6.18 \\
& 5 & 4.24 & -6.40 & 4.26 & -5.96 \\
\hline
\end{tabular}

\subsection{Identification of global bridge stiffness}

Using the forces obtained from the algorithm outlined in Section 3, a new algorithm is developed which aims to identify a damage sensitive bridge parameter. In particular, the global bridge stiffness, EJ, is the focus of this algorithm as a reduction in stiffness would result from a loss of cross-section or cracking; with increased loading this decrease can worsen (MacGregor and Wight 2006, Lee and Yun 2008). It has been the focus of many damage assessment techniques which take direct measurements on the structure (Sohn et al. 2003, Carden and Fanning 2004), in part due to its relationship with cracking (Dimarogonas 1996). This algorithm aims to provide an alternative low-cost, efficient tool for widespread monitoring of overall structural changes that could warn a bridge operator if the bridge is becoming unsafe and highlight those bridges in a network where more detailed inspection is 
required e.g., via specialised installations on the bridge. Therefore, this approach is aimed at achieving a preliminary assessment of bridge condition through identification of the global stiffness of the bridge.

\section{Stiffness Identification algorithm}

The stiffness identification algorithm involves an iterative procedure comprising of five main steps. A similar algorithm has been employed by González et al. (2012) for the purpose of bridge damping identification. In this study, the algorithm requires that the dynamic forces, $F_{t, i}$ and the total displacements under each wheel, $w_{v, i}$, have been calculated previously using the VFI algorithm from Section 3. The target bridge stiffness values to be identified are given in Table 2. An overview of the adapted algorithm is presented in Fig. 10.

The first step involves calculating the vector of total contact forces ( $\left.\mathbf{f}_{\mathbf{i n t}}\right)$ using Eq. (6). In the second step, a linear correction is applied to the displacements $w_{v, i}$ to ensure that the condition stated in Eq. (21) is maintained. The correction is a linear function which varies with distance along the bridge and it is based on the true bridge displacement being zero at the entrance and the exit to the bridge, i.e., the only displacement a wheel experiences at these locations is the road profile height. This means that the (true) total displacement under wheel 1 when it is located over a support should be equal to the total displacement under wheel 2 when it is located over the same support.

$$
w_{v, 1}\left(x_{b}, t_{1}\right)-w_{v, 2}\left(x_{b}, t_{2}\right)=0 ; x_{b}=0, L
$$


where $x_{b}$ is the distance along the bridge and $t_{1}$ and $t_{2}$ correspond to the times when axle 1 or axle 2 are at support location $x_{b}$ respectively. Based on the axle spacing of $4.75 \mathrm{~m}$ and a speed of $80 \mathrm{~km} / \mathrm{h}, t_{1}-t_{2}=0.214$ seconds.

In the third step, the total contact forces, $\mathbf{f}_{\mathbf{i n t}}$, obtained in the first step are applied directly to the FE beam model described in Section 2.3. An estimate of the stiffness, $E J_{\text {est }}$, is given to the beam to obtain the displacement vector $\mathbf{w}_{\mathbf{b}}$ due to the moving loads in $\mathbf{f}_{\text {int }}$ (Eq. (5)). Then, the displacement response of the beam, $w_{b, i}$, under each wheel is calculated using Eq. (7). This process is repeated for stiffness estimates ranging from $10^{5}$ to $9 \times 10^{14}$. These estimates can be represented by $\left(a \times 10^{b}\right) \mathrm{N} \mathrm{m}^{2}$ where the coefficient $a$ ranges from 1 to 9 in steps of 0.1. The power $b$ ranges from 5 to 14 in steps of 1 . The true stiffness value is also included as an estimate therefore this gives a total of 811 stiffness estimates for the beam, which in turn provides 811 estimates of $w_{b, i}$ for wheel $i$.

In the fourth step, Eq. (4) is rearranged to obtain road profile height estimates, $r_{e s t, i}$, under each wheel for each stiffness estimate by subtracting each range of $w_{b, i}$ (step 3) from the total displacements $w_{v, i}$ obtained using the VFI algorithm:

$$
r_{e s t, i}=w_{v, i}-w_{b, i} ; i=1,2
$$

As it has been shown that the VFI algorithm is most accurate for a particular band of frequencies, a band pass filter, with lower and upper cut-off frequencies of 1 and $40 \mathrm{~Hz}$ respectively, is applied to the profile estimates, $r_{e s t, i}$. 
In the fifth and final step, the global bridge stiffness is identified. As the wheels follow each other along the same wheel path, the profile estimates under each wheel $\left(r_{e s t, 1}\right.$ and $\left.r_{e s t, 2}\right)$ should be very close for the correct stiffness value. A least squares error minimisation process is used to identify the optimal stiffness value from the range of estimates investigated. It consists of a summation over all measurements in time, $t$. The optimal solution is identified as the stiffness estimate which provides the minimum least squares error between the profile estimates under each wheel (Eq. (23)).

$$
r_{\text {error }}=\sum_{t}\left(r_{\text {est }, 1}-r_{e s t, 2}\right)^{2}
$$

The average computational time required for this algorithm is only 30 seconds with a $3 \mathrm{GHz}$ processor, 6MB cache and 3072MB SDRAM running on Matlab. 


\section{Calculate Vector of Total Contact Forces, $\mathbf{f}_{\text {int }}(\mathbf{N})$}

- Dynamic axle forces, $F_{t, i}$, are obtained using the VFI algorithm presented in Section 3

- Evaluate Eq. (6)

\section{Apply Linear Correction to Displacements under wheel, $w_{v, i}(\mathrm{~m})$}

- Total displacements under each wheel, $w_{v, i}$, are obtained using the VFI algorithm presented in Section 3

\section{Estimate Bridge Displacement under wheel, $w_{b, i}(\mathrm{~m})$}

- Apply total contact forces $\mathbf{f}_{\mathbf{i n t}}$ to FE beam for stiffness estimates, $E J_{\text {est }}$, ranging from $10^{5}$ to $9 \times 10^{14}$ in steps of 0.1 , and solve Eq. (5)

- Evaluate Eq. (7) to obtain $w_{b, i}$

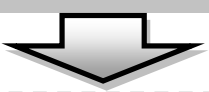

\section{Calculate Estimated Road Profile Heights $\boldsymbol{r}_{e s t, i}(\mathrm{~m})$ for all $E J_{\text {est }}$ using} Eq. (22)

- Apply band pass filter to the profile estimates, $r_{e s t, i}$, with cutoff frequencies of $1 \mathrm{~Hz}$ and $40 \mathrm{~Hz}$

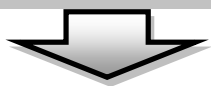

\section{Identification of Global Bridge Stiffness}

- Identify stiffness which minimises the error between road profile estimations under wheels 1 and 2 using Eq. (23)

Fig. 10 Bridge stiffness identification algorithm

\section{Results of simulation}

The algorithm is tested for the three bridge spans given in Table 2, very good and average road profiles and for SNRs of 20,10 and 5. An example of the least squares error between the profile heights under the first and second wheels (Eq. (23)) is plotted on a log-log scale 
against the stiffness estimates in Fig. 11 for the very good road profile simulation. This illustrates that the minimum, as expected, corresponds to the true stiffness value for the $15 \mathrm{~m}$ bridge span. The percentage errors of the algorithm in estimating the bridge stiffness value for each of the three bridge spans investigated are given in Table 6.
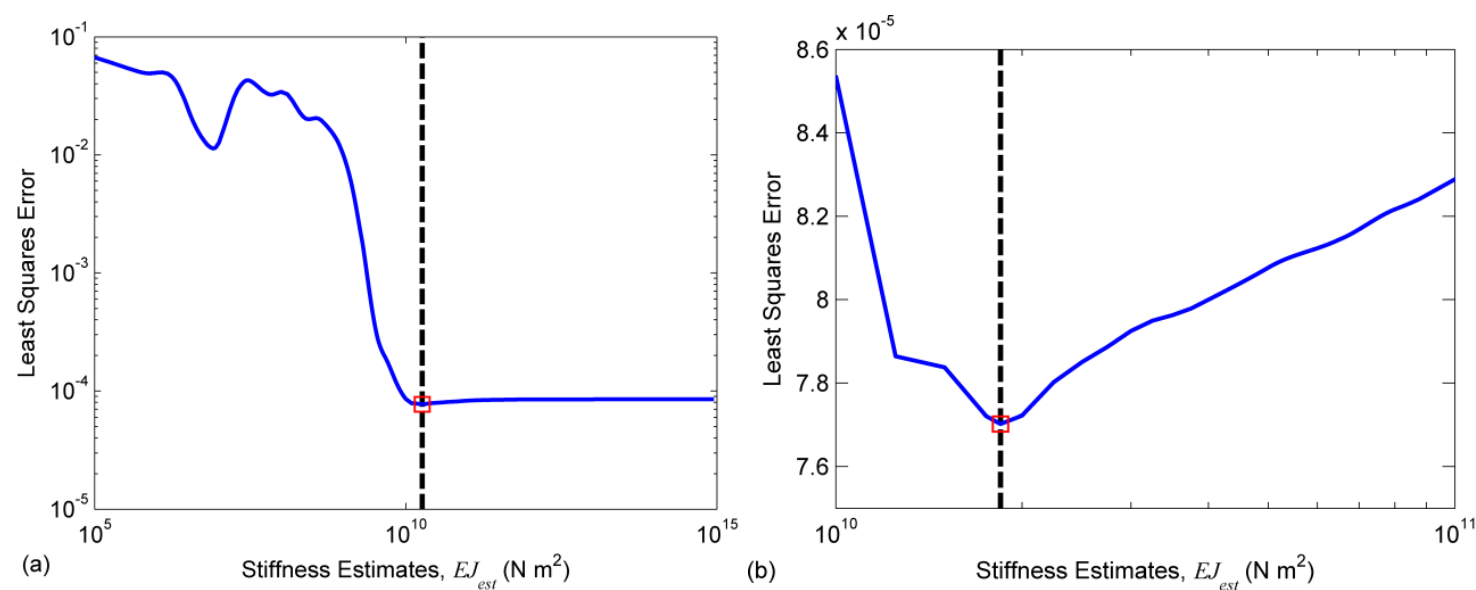

Fig. 11 (a) Least squares error, $r_{\text {error }}(-)$ versus global stiffness estimates $\left(E J_{\text {est }}\right)$ for $15 \mathrm{~m}$ bridge span with SNR = 20, (b) same graph, zoomed in at minimum ( $\square$ ). Target stiffness value is $1.846 \times 10^{10} \mathrm{~N} \mathrm{~m}^{2}(\mathbf{-}-\mathbf{-})$.

For the very good (Class A) profile the algorithm is very accurate, especially for lower levels of noise. This high accuracy is maintained for all noise levels for the $15 \mathrm{~m}$ bridge span while a decrease in accuracy occurs with increasing noise level for the $25 \mathrm{~m}$ and $35 \mathrm{~m}$ spans. This suggests that, for a very good road profile, this approach could be very effective. For the average (Class C) profile the algorithm accuracy decreases, considerably for the $15 \mathrm{~m}$ span, which suggests that this approach is sensitive to road roughness. Also, the trend with increasing noise is not repeated for this profile, except for the predicted stiffness values of the $35 \mathrm{~m}$ span, which are very good for low and medium noise levels. 
Table 6 Percentage error in identified bridge stiffness values

\begin{tabular}{|c|c|c|c|c|c|c|}
\hline \multirow[b]{3}{*}{ SNR } & \multicolumn{6}{|c|}{ Span (m) } \\
\hline & \multicolumn{2}{|c|}{15} & \multicolumn{2}{|c|}{25} & \multicolumn{2}{|c|}{35} \\
\hline & $\begin{array}{l}\% \text { Error } \\
\text { Class A } \\
\end{array}$ & $\begin{array}{l}\% \text { Error } \\
\text { Class C }\end{array}$ & $\begin{array}{l}\% \text { Error } \\
\text { Class A }\end{array}$ & $\begin{array}{l}\% \text { Error } \\
\text { Class C }\end{array}$ & $\begin{array}{l}\% \text { Error } \\
\text { Class A } \\
\end{array}$ & $\begin{array}{l}\% \text { Error } \\
\text { Class C }\end{array}$ \\
\hline 20 & 0 & -45.8 & 0.3 & -17.8 & 0 & 0 \\
\hline 10 & 0.2 & -34.9 & -2.4 & -17.8 & -1.3 & 0.4 \\
\hline 5 & 0.2 & -13.3 & -7.5 & -17.8 & 10 & 17.1 \\
\hline
\end{tabular}

The sensitivity to road roughness can be explained by the contribution of the bridge displacement, $w_{b, i}$, to the predicted displacements under each wheel, $w_{v, i}$. Referring to Eq. (4), the road profile heights, $r_{i}$, form a larger proportion of the total displacement under each wheel, relative to the bridge displacements, $w_{b, i}$. As the roughness of the road profile increases, the ratio of the road profile heights to the bridge displacements increases. Hence the predicted $w_{v, i}$ is less sensitive to changes in the bridge response. Therefore, for increased road roughness, the algorithm is less sensitive to changes in stiffness. This is confirmed in Table 6 - bridge displacement increases with bridge span length and for the average road profile, in general, the stiffness errors decrease with bridge span length. To improve the accuracy for rougher road profiles, a heavier vehicle could be used to increase the bridge displacement relative to the road profile heights (the vehicle used for this study is $18 \mathrm{t}$ ).

\section{Conclusions}

This paper first presents a novel method for the identification of dynamic vehicle forces from vehicle acceleration measurements. Moving force identification theory is applied to the equations of motion of the vehicle in order to obtain the dynamic forces. The method is 
numerically validated for a range of bridge spans, measurement noise levels and road profiles. In the case of simulations for very good and average road profiles, the method identifies the forces very well. Due to the smoothing of the solution by regularisation, some higher frequency components of the forces are not predicted well. Overall, it is found that the vehicle force identification method is insensitive to noise which is an advantage of the approach.

The implementation of this approach as a drive-by inspection tool for bridges and pavements is also presented. It is found that the method is quite accurate in detecting road profile heights and is insensitive to the road roughness. However, as for the identified forces, errors at high frequency occur. Some errors at very long wavelength/low frequency occur also so an intermediate frequency band within which the approach is very accurate, is established.

An algorithm for the identification of global bridge stiffness using the identified vehicle forces from a bridge crossing is presented. It is found to be very accurate for a very good road profile; with a signal to noise ratio of 20 the stiffness estimation errors are less than $0.5 \%$. The accuracy decreases with increasing noise level but for the highest SNR of 5, estimates are within $10 \%$ of the true stiffness value. For the average road profile the algorithm is not as accurate and it is dependent on the bridge span length and the ratio of the road profile heights to the bridge deflection.

In the field it is likely that there are a number of factors that will reduce the accuracy of the algorithms presented in this paper (e.g., inaccuracies in the assumed bridge or vehicle model). Nevertheless, the positive results in this theoretical investigation suggest that it has the potential to be implemented as a sensitive low-cost method of identifying dynamic vehicle 
axle forces. It also has the potential to be used for condition monitoring of pavements and the identification of global bridge stiffness in short to medium span bridges.

\section{Acknowledgement}

The authors wish to express their gratitude for the financial support received from the $7^{\text {th }}$

European Framework ASSET (Advanced Safety and Driver Support in Efficient Road Transport) project towards this investigation.

\section{Appendix A}

$\mathbf{M}_{\mathbf{v}}=\left[\begin{array}{cccc}m_{s} & 0 & 0 & 0 \\ 0 & I_{s} & 0 & 0 \\ 0 & 0 & m_{u, 1} & 0 \\ 0 & 0 & 0 & m_{u, 2}\end{array}\right]$

$\mathbf{C}_{\mathbf{v}}=\left[\begin{array}{cccc}C_{s, 1}+C_{s, 2} & D_{1} C_{s, 1}-D_{2} C_{s, 2} & -C_{s, 1} & -C_{s, 2} \\ D_{1} C_{s, 1}-D_{2} C_{s, 2} & D_{1}{ }^{2} C_{s, 1}+D_{2}{ }^{2} C_{s, 2} & -D_{1} C_{s, 1} & D_{2} C_{s, 2} \\ -C_{s, 1} & -D_{1} C_{s, 1} & C_{s, 1} & 0 \\ -C_{s, 2} & D_{2} C_{s, 2} & 0 & C_{s, 2}\end{array}\right]$

$\mathbf{K}_{\mathbf{v}}=\left[\begin{array}{cccc}K_{s, 1}+K_{s, 2} & D_{1} K_{s, 1}-D_{2} K_{s, 2} & -K_{s, 1} & -K_{s, 2} \\ D_{1} K_{s, 1}-D_{2} K_{s, 2} & D_{1}^{2} K_{s, 1}+D_{2}^{2} K_{s, 2} & -D_{1} K_{s, 1} & D_{2} K_{s, 2} \\ -K_{s, 1} & -D_{1} K_{s, 1} & K_{s, 1} & 0 \\ -K_{s, 2} & D_{2} K_{s, 2} & 0 & K_{s, 2}\end{array}\right]$

$\mathbf{K}_{\mathbf{v v}}=\left[\begin{array}{cccc}K_{s, 1}+K_{s, 2} & D_{1} K_{s, 1}-D_{2} K_{s, 2} & -K_{s, 1} & -K_{s, 2} \\ D_{1} K_{s, 1}-D_{2} K_{s, 2} & D_{1}{ }^{2} K_{s, 1}+D_{2}{ }^{2} K_{s, 2} & -D_{1} K_{s, 1} & D_{2} K_{s, 2} \\ -K_{s, 1} & -D_{1} K_{s, 1} & K_{s, 1}+K_{t, 1} & 0 \\ -K_{s, 2} & D_{2} K_{s, 2} & 0 & K_{s, 2}+K_{t, 2}\end{array}\right]$

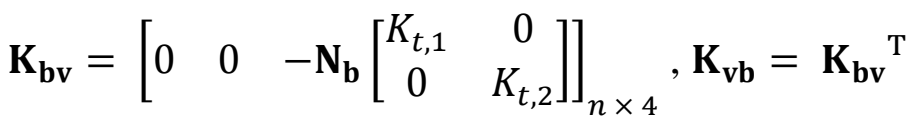

$\mathbf{K}_{\mathbf{b b}}=\left[\mathbf{N}_{\mathbf{b}}\left[\mathbf{N}_{\mathbf{b}}\left[\begin{array}{cc}K_{t, 1} & 0 \\ 0 & K_{t, 2}\end{array}\right]\right]^{\mathrm{T}}\right]_{n \times n}$

$\mathbf{M}_{\mathbf{g}}=\left[\begin{array}{cc}\mathbf{M}_{\mathbf{v}} & 0 \\ 0 & \mathbf{M}_{\mathbf{b}}\end{array}\right], \mathbf{C}_{\mathbf{g}}=\left[\begin{array}{cc}\mathbf{C}_{\mathbf{v}} & 0 \\ 0 & \mathbf{C}_{\mathbf{b}}\end{array}\right], \mathbf{K}_{\mathbf{g}}=\left[\begin{array}{cc}\mathbf{K}_{\mathbf{v v}} & \mathbf{K}_{\mathbf{v b}} \\ \mathbf{K}_{\mathbf{b v}} & \mathbf{K}_{\mathbf{b}}+\mathbf{K}_{\mathbf{b b}}\end{array}\right]$ 
$\mathbf{f}=\left\{\begin{array}{c}0 \\ 0 \\ K_{t, 1} r_{1} \\ K_{t, 2} r_{2} \\ \mathbf{N}_{\mathbf{b}}\left\{\begin{array}{l}P_{1}-K_{t, 1} r_{1} \\ P_{2}-K_{t, 2} r_{2}\end{array}\right\}\end{array}\right\}$

$\mathbf{N}_{\mathbf{b}}=\left[\begin{array}{cc}0 & 0 \\ N_{1} & 0 \\ 0 & N_{2} \\ 0 & 0\end{array}\right]_{n \times 2}$

The location matrix $\mathbf{N}_{\mathbf{b}}$ will contain zero entries everywhere bar the locations of the degrees of freedom which correspond to the nodal displacements and rotations of the beam elements the vehicle is in contact with. It should be noted that entries corresponding to the boundary conditions will also be zero. The Hermitian shape function $N_{i}$ for the $i$ th interaction force located on an element $j$ can be written in global coordinates as

$$
N_{i}=\left\{\begin{array}{c}
1-3\left(\frac{x_{i}-(j-1) l}{l}\right)^{2}+2\left(\frac{x_{i}-(j-1) l}{l}\right)^{3} \\
\left(x_{i}-(j-1) l\right)-\frac{2\left(x_{i}-(j-1) l\right)^{2}}{l}+\frac{\left(x_{i}-(j-1) l\right)^{3}}{l^{2}} \\
3\left(\frac{x_{i}-(j-1) l}{l}\right)^{2}-2\left(\frac{x_{i}-(j-1) l}{l}\right)^{3} \\
-\frac{\left(x_{i}-(j-1) l\right)^{2}}{l}+\frac{\left(x_{i}-(j-1) l\right)^{3}}{l^{2}}
\end{array}\right\}
$$

where $l$ is the length of the beam element and $(j-1) l \leq x_{i} \leq j l$.

\section{References}

Adhikari, S. (2006), "Damping modelling using generalized proportional damping”, J. Sound Vibr., 293, 156-170. 
Asmussen, J.C., Ibrahim, S.R. and Brincker, R. (1998), "Random Decrement Identification of Structures Subjected to Ambient Excitation", SEM Proceedings of the International Modal Analysis Conference, February 1998, 914-921.

Au, F.T.K., Jiang, R.J. and Cheung, Y.K. (2004), "Parameter identification of vehicles moving on continuous bridges", J. Sound Vibr., 269, 91-111.

Bathe, K.J. and Wilson, E.L. (1976), Numerical methods in finite element analysis. Prentice Hall.

Busby, H.R. and Trujillo, D.M. (1997), “Optimal regularization of an inverse dynamics problem”, Comput. Struct., 63(2), 243-248.

BS5400 (1990), "Steel, concrete and composite bridges - Part 4: Code of practice for design of concrete bridges".

Carden, E.P. and Fanning, P. (2004), "Vibration based condition monitoring: A review", Struct. Health Monit., 3(4), 355-377.

Cebon, D. (1987), “Assessment of the dynamic wheel forces generated by heavy road vehicles", Proceedings of ARRB/FORS Symposium on Heavy vehicle suspension characteristics, Canberra, Australia, 143-162.

Cebon, D. (1999), Handbook of vehicle-road interaction, Swets and Zeitlinger Publishers, Lisse, The Netherlands.

Chan, T.H.T., Law, S.S. and Yung, T.H. (1999), “An interpretive method for moving force identification”, J. Sound Vibr., 219(3), 503-524.

Chan, T.H.T. and Yung, T.H. (2000), “A theoretical study of force identification using prestressed concrete bridges", Eng. Struct., 23, 1529-1537. 
Chang, G.K., Dick, J.C. and Rasmussen, R.O. (2006), ProVAL Users guide, The Transtec Group, Inc.

Clough, R.W. and Penzien, J. (1993), Dynamics of structures, McGraw-Hill.

Cole, D.J. and Cebon, D. (1992), "Spatial repeatability of dynamic tyre forces generated by heavy vehicles", Proceedings of the Institution of Mechanical Engineers, Part D, 206(D1), 17-27.

Cole, D.J., Collop, A.C., Potter, T.E.C. and Cebon, D. (1996), "Spatial repeatability of measured dynamic tyre forces", Proceedings of the Institution of Mechanical Engineers, Part D, 210(D3), 185-197.

DAF Trucks Limited (2011), FA LF55 18t Specification sheet, DAF Trucks Limited.

Davis, L., and Bunker, J. (2007), Heavy Vehicle Suspensions - Testing and Analysis. A literature review, Brisbane, Queensland: Queensland Department of Main Roads, Queensland University of Technology, Australia.

Deng, L. and Cai, C.S. (2010a), "Development of dynamic impact factor for performance evaluation of existing multi-girder concrete bridges”, Eng. Struct., 32(1), 21-31.

Deng, L. and Cai, C.S. (2010b), "Identification of Dynamic Vehicular Axle Loads: Theory and Simulations", J. Vib. Control, 16(14), 2167-2194.

Deng, L. and Cai, C.S. (2011), "Identification of Dynamic Vehicular Axle Loads: Demonstration by a Field Study", J. Vib. Control, 17(2), 183-195.

Dimarogonas, A.D. (1996), "Vibration of cracked structures-a state of the art review", Eng. Frac. Mech., 55(5), 831-857. 
DIVINE (1997), "Dynamic interaction of heavy vehicles with roads and bridges", Technical report, OECD, Ottawa, Canada. DIVINE Concluding Conference, 1997.

Friswell, M.I. and Mottershead, J.E. (1995), Finite element model updating in structural dynamics, Springer, 286 pages.

Gillespie, T.D., Karamihas, S.M., Cebon, D., Sayers, M.W., Nasim, M.A., Hansen, W. and Ehsan, N. (1992), Effects of heavy vehicle characteristics on $p$ response and performance, University of Michigan Transportation Research Institute, UMTRI-92-2.

González, A., OBrien, E.J., Li, Y.-Y. and Cashell, K. (2008a), "The use of vehicle acceleration measurements to estimate road roughness", Veh. Syst. Dyn., 46(6), 483499.

González, A., Rowley, C. and OBrien, E.J. (2008b), “A general solution to the identification of moving vehicle forces on a bridge", Int. J. Numer. Methods Eng., 75(3), 335-354.

González, A., OBrien, E.J. and McGetrick, P.J. (2010), "Detection of Bridge Dynamic Parameters Using an Instrumented Vehicle", Proceedings of the Fifth World Conference on Structural Control and Monitoring, Tokyo, Japan (2010), paper 34.

González, A. (2010), "Vehicle-bridge dynamic interaction using finite element modelling", In: David Moratal (Ed.). Finite Element Analysis. Sciyo, Croatia, 637-662.

González, A., Cantero, D., OBrien, E.J. (2011), “Dynamic increment for shear force due to heavy vehicles crossing a highway bridge”, Comput. Struct., 89(23-24), 2261-2272.

González, A., OBrien, E.J. and McGetrick, P.J. (2012), "Identification of damping in a bridge using a moving instrumented vehicle”, J. Sound Vibr., 331(18), 4115-4131. 
Green, M.F. and Cebon, D. (1994), "Dynamic responses of highway bridges to heavy vehicle loads, theory and experimental validation", J. Sound Vibr., 170(1), 51-78.

Gutenbrunner, G., Savov, K. and Wenzel, H. (2007), "Sensitivity Studies on Damping Estimation", Proceedings of the Second International Conference on Experimental Vibration Analysis for Civil Engineering Structures (EVACES), Porto, Portugal.

Hansen, P.C. (1992), "Analysis of discrete ill-posed problems by means of the L-curve", SIAM Review, 34(4), 561-580.

Harris, N.K., OBrien, E.J. and González, A. (2007), "Reduction of bridge dynamic amplification through adjustment of vehicle suspension damping", J. Sound Vibr., 302(3), 471-485.

Harris, N.K., González, A., OBrien, E.J. and McGetrick, P.J. (2010), “Characterisation of pavement profile heights using accelerometer readings and a combinatorial optimisation technique", J. Sound Vibr., 329, 497-508.

Henchi, K., Fafard, M., Talbot, M. and Dhatt, G. (1998), “An efficient algorithm for dynamic analysis of bridges under moving vehicles using a coupled modal and physical components approach", J. Sound Vibr., 212(4), 663-683.

Ibrahim, S.R. (1977), "Random decrement technique for modal identification of structures", The AIAA Journal of Spacecraft and Rockets, 14(11), 696-700.

International Organization for Standardization ISO (1995), Mechanical vibration - Road surface profiles - Reporting of measure data, ISO8608 (BS7853:1996).

Jiang, R.J., Au, F.T.K. and Cheung, Y.K. (2004), "Identification of vehicles moving on continuous bridges with rough surface”, J. Sound Vibr., 274, 1045-1063. 
Kim, C.W., Kawatani, M. and Kim, K.B. (2005), “Three-dimensional dynamic analysis for bridge-vehicle interaction with roadway roughness", Comput. Struct., 83, 1627-1645.

Kim, C.W. and Kawatani, M. (2009), "Challenge for a Drive-by Bridge Inspection", Proceedings of the 10th International Conference on Structural Safety and Reliability, ICOSSAR2009, Osaka, Japan, 2009, 758-765.

Kitching, J., Cole, D.J. and Cebon, D. (2000), "Theoretical investigation into the use of controllable suspensions to minimize road damage", Proceedings of the Institution of Mechanical Engineers, Part D: Journal of Automobile Engineering, 214, 13-31.

Law, S.S., Chan, T.H.T. and Zeng, Q.H. (1997), "Moving force identification: a time domain method", J. Sound Vibr., 201, 1-22.

Law, S.S. and Zhu, X.Q. (2000), "Study on different beam models on moving force identification", J. Sound Vibr., 234(4), 661-679.

Law, S.S. and Fang, Y.L. (2001), "Moving force identification: optimal state estimation approach", J. Sound Vibr., 239(2), 233-254.

Law, S.S., Chan, T.H.T., Zhu, X.Q. and Zeng, Q.H. (2001), "Regularization in moving force identification", J. Eng. Mech.(ASCE), 127(2), 136-148.

Law, S.S., Bu, J.Q., Zhu, X.Q. and Chan, S.L. (2004), "Vehicle axle loads identification using finite element method", Eng. Struct., 26, 1143-1153.

Law, S.S., Bu, J.Q., Zhu, X.Q. and Chan, S.L. (2007), "Moving load identification on a simply supported orthotropic plate”, Int. J. Mech. Sci., 49, 1262-1275. 
Lee, K.J. and Yun, C.B. (2008), "Parameter identification for nonlinear behavior of RC bridge piers using sequential modified extended Kalman filter”, Smart Struct. Syst., 4(3), 319342.

Li, Y.-Y. (2006), "Factors affecting the dynamic interaction of bridges and vehicle loads", Ph.D. Thesis, Department of Civil Engineering, University College Dublin, Ireland.

Li, Y.-Y., OBrien, E.J. and Gonzalez, A. (2006), "The development of a dynamic amplification estimator for bridges with good road profiles", J. Sound Vibr., 293(1-2), $125-137$.

Lin, C.W. and Yang, Y.B. (2005), "Use of a passing vehicle to scan the fundamental bridge frequencies. An experimental verification”, Eng. Struct., 27, 1865-1878.

Liu, T.Y., Chiang, W.L., Chen, C.W., Hsu, W.K., Lu, L.C. and Chu, T.J. (2011), "Identification and monitoring of bridge health from ambient vibration data", J. Vibr. Control, 17(4), 589-603.

Lourens, E., Reynders, E., De Roeck, G., Degrande, G. and Lombaert, G. (2012), “An augmented Kalman filter for force identification in structural dynamics", Mech. Syst. Signal Proc., 27, 446-460.

MacGregor, J.G. and Wight J.K. (2006), Reinforced Concrete: Mechanics and Design - 4th Edition in SI Units, Prentice Hall.

MATLAB (2005), The MathWorks, Inc., MATLAB, Version 7, USA. http://www.mathworks.com

McGetrick, P.J., González, A. and OBrien, E.J. (2009), “Theoretical investigation of the use of a moving vehicle to identify bridge dynamic parameters", Insight, 51(8), 433-438. 
Nagayama, T., Sim, S.H., Miyamori, Y., Spencer Jr, B.F., (2007), “Issues in structural health monitoring employing smart sensors", Smart Struct. Syst., 3(3), 299-320.

Nordström, L.J.L. (2006), “A dynamic programming algorithm for input estimation on linear time-variant systems", Comput. Meth. Appl. Mech. Eng., 195, 6407-6427.

Oshima, Y., Yamaguchi, T., Kobayashi, Y. and Sugiura, K. (2008), "Eigenfrequency estimation for bridges using the response of a passing vehicle with excitation system", Proceedings of the Fourth International Conference on Bridge Maintenance, Safety and Management, IABMAS2008, Seoul, Korea, 2008, 3030-3037.

Pinkaew, T. (2006), "Identification of vehicle axle loads from bridge responses using updated static component technique”, Eng. Struct., 28, 1599-1608.

Pinkaew, T. and Asnachinda, P. (2007), "Experimental study on the identification of dynamic axle loads of moving vehicles from the bending moments of bridges”, Eng. Struct., 29, 2282-2293.

Qu, W.L., Wang, Y., and Pi, Y.L. (2011), "Multi-axle moving train loads identification on simply supported bridge by using simulated annealing genetic algorithm", Int. J. Struct. Stab. Dyn., 11(1), 57-71.

Sayers, M.W. and Karamihas, S.M. (1996), Interpretation of road profile roughness data, University of Michigan Transportation Research Institute, UMTRI-96-19.

Sayers, M.W. and Karamihas, S.M. (1998), The little book of profiling, University of Michigan Transportation Research Institute, UMTRI-96-19. 
Sohn, H., Farrar, C.R., Hemez, F.M., Shunk, D.D., Stinemates, D.W. and Nadler, B.R. (2003), A review of structural health monitoring literature: 1996-2001, Los Alamos National Laboratory Report LA-13976-MS, USA.

Tedesco, J.W., McDougal, W.G. and Ross, C.A. (1999), Structural Dynamics, Theory and Applications, Addison-Wesley.

Tikhonov, A.N. and Arsenin, V.Y. (1977), Solutions of Ill-posed Problems, Wiley: New York.

Toshinami, T., Kawatani, M. and Kim, C.W. (2010), "Feasibility investigation for identifying bridge's fundamental frequencies from vehicle vibrations", Proceedings of the Fifth International Conference on Bridge Maintenance, Safety and Management, IABMAS2010, Philadelphia, USA, 2010, 317-322.

Trujillo, D.M. (1978), “Application of dynamic programming to the general inverse problem”, Int. J. Numer.Methods Eng., 12, 613-624.

Trujillo, D.M. and Busby, H.R. (1997), Practical Inverse Analysis Engineering, CRC Press: New York.

Wang, Y. and Qu, W.L. (2011), “Moving Train Loads Identification on a Continuous Steel Truss Girder by Using Dynamic Displacement Influence Line Method”, Int. J. Steel Struct., 11(2), 109-115.

Weaver, W. and Johnston, P.R. (1987), Structural Dynamics by Finite Elements, PrenticeHall, UK.

Wu, S.Q. and Law, S.S. (2011), "Vehicle axle load identification on bridge deck with irregular road surface profile", Eng. Struct., 33, 591-601. 
Yang, Y.B. and Yau, J.D. (1997), "Vehicle-bridge interaction element for dynamic analysis”, J. Struct. Eng., 123(11), 1512-1518.

Yang, Y.B., Yau, J.D. and Wu, Y.S. (2004a), Vehicle-Bridge Interaction Dynamics. With Applications to High-Speed Railways, World Scientific Publishing Co., ISBN 981-238847-8, Singapore.

Yang, Y.B., Lin, C.W. and Yau, J.D. (2004b), "Extracting bridge frequencies from the dynamic response of a passing vehicle", J. Sound Vibr., 272, 471-493.

Yang, Y.B. and Chang, K.C. (2009a), "Extraction of bridge frequencies from the dynamic response of a passing vehicle enhanced by the EMD technique", J. Sound Vibr., 322, $718-739$.

Yang, Y.B. and Chang, K.C. (2009b), "Extracting the bridge frequencies indirectly from a passing vehicle: Parametric study", Eng. Struct., 31(10), 2448-2459.

Yu, L. and Chan T.H.T. (2003a), "Moving force identification based on the frequency-time domain method", J. Sound Vibr., 261, 329-349.

Yu, L. and Chan, T.H.T. (2003b), "Identification of multi-axle vehicle loads on bridges", $J$. Vib. Acoust. (ASME), 126(1), 17-26.

Yu, L. and Chan, T.H.T. (2007), "Recent research on identification of moving loads on bridges", J. Sound Vibr., 305, 3-21.

Zhu, X.Q. and Law, S.S. (1999), "Moving forces identification on a multi-span continuous bridge", J. Sound Vibr., 228(2), 377-396.

Zhu, X.Q. and Law, S.S. (2000), "Identification of vehicle axle loads from bridge dynamic responses", J. Sound Vibr., 236(4), 705-724. 
Zhu, X.Q. and Law, S.S. (2001a), "Orthogonal function in moving loads identification on a multi-span bridge", J. Sound Vibr., 245(2), 329-345.

Zhu, X.Q. and Law, S.S. (2001b), "Identification of moving loads on an orthotropic plate", J. Vib. Acoust., 123(2), 238-244.

Zhu, X.Q. and Law, S.S. (2002), “Moving loads identification through regularization”, J. Eng. Mech. (ASCE), 128(9), 989-1000.

Zhu, X.Q. and Law, S.S. (2003a), "Identification of moving interaction forces with incomplete velocity information”, Mech. Syst. Signal Proc., 17(6), 1349-1366.

Zhu, X.Q. and Law, S.S. (2003b), “Time domain identification of moving loads on bridge deck", J. Vib. Acoust., 125(2), 187-198.

Zhu, X.Q. and Law, S.S. (2006), "Moving load identification on multi-span continuous bridges with elastic bearings", Mech. Syst. Signal Proc., 20(7), 1759-1782. 